\title{
Phylogenetic analysis of higher-level relationships within Hydroidolina (Cnidaria: Hydrozoa) using mitochondrial genome data and insight into their mitochondrial transcription
}

Ehsan Kayal, Bastian Bentlage, Paulyn Cartwright, Angel A Yanagihara, Dhugal J Lindsay, Russell R Hopcroft, Allen G Collins

Hydrozoans display the most morphological diversity within the phylum Cnidaria. While recent molecular studies have provided some insights into their evolutionary history, sister group relationships remain mostly unresolved, particularly at mid-taxonomic levels. Specifically, within Hydroidolina, the most speciose hydrozoan subclass, the relationships and sometimes integrity of orders are highly unsettled. Here we obtained the near complete mitochondrial sequence of twenty-six hydroidolinan hydrozoan species from a range of sources (DNA and RNA-seq data, long-range PCR). Our analyses confirm previous inference of the evolution of mtDNA in Hydrozoa while introducing a novel genome organization. Using RNA-seq data, we propose a mechanism for the expression of mitochondrial mRNA in Hydroidolina that can be extrapolated to the other medusozoan taxa. Phylogenetic analyses using the full set of mitochondrial gene sequences provide some insights into the order-level relationships within Hydroidolina, including siphonophores as the first diverging clade, a well-supported clade comprised of Leptothecata-Filifera III-IV, and a second clade comprised of Aplanulata-Capitata s.S.Filifera I-II. Finally, we describe our relatively inexpensive and accessible multiplexing strategy to sequence long-range PCR amplicons that can be adapted to most highthroughput sequencing platforms. 
1 Phylogenetic analysis of higher-level relationships within Hydroidolina (Cnidaria: Hydrozoa) using

2 mitochondrial genome data and insight into their mitochondrial transcription

3

4 Ehsan Kayal, Department of Invertebrate Zoology, National Museum of Natural History, Smithsonian Institution,

$5 \quad$ MRC-163, PO Box 37012, Washington DC, USA

6 Bastian Bentlage, Department of Invertebrate Zoology, National Museum of Natural History, Smithsonian

7 Institution, MRC-163, PO Box 37012, Washington DC, USA

8 Paulyn Cartwright, Department of Ecology and Evolutionary Biology, University of Kansas, Lawrence, KS, USA

9 Angel Yanagihara, Department of Tropical Medicine, Medical Microbiology and Pharmacology, John A. Burns

10 School of Medicine, University of Hawaii at Manoa, Honolulu, HI, USA

11 Dhugal J. Lindsay, Japan Agency for Marine-Earth Science and Technology (JAMSTEC), 237-0061 Yokosuka, 12 Japan

13

Russell R. Hopcroft, Institute of Marine Science, University of Alaska Fairbanks, Fairbanks AK, USA

14 Allen G. Collins, Department of Invertebrate Zoology, National Museum of Natural History, Smithsonian

15 Institution, MRC-163, PO Box 37012, Washington DC, USA \& National Systematics Laboratory of NOAA's

16 Fisheries Service, National Museum of Natural History, Washington, DC. USA

17

Corresponding author: Ehsan Kayal, Department of Invertebrate Zoology, National Museum of Natural History,

Smithsonian Institution, MRC-163, PO Box 37012, Washington DC, USA. Tel: 515-231-8453. Email:

20 kayale@si.edu. 


\section{Abstract}

22 Hydrozoans display the most morphological diversity within the phylum Cnidaria. While recent molecular studies have provided some insights into their evolutionary history, sister group relationships remain mostly unresolved, particularly at mid-taxonomic levels. Specifically, within Hydroidolina, the most speciose hydrozoan subclass, the relationships and sometimes integrity of orders are highly unsettled. Here we obtained the near complete mitochondrial sequence of twenty-six hydroidolinan hydrozoan species from a range of sources (DNA and RNA-seq data, long-range PCR). Our analyses confirm previous inference of the evolution of mtDNA in Hydrozoa while introducing a novel genome organization. Using RNA-seq data, we propose a mechanism for the expression of mitochondrial mRNA in Hydroidolina that can be extrapolated to the other medusozoan taxa. Phylogenetic analyses using the full set of mitochondrial gene sequences provide some insights into the order-level relationships within Hydroidolina, including siphonophores as the first diverging clade, a well-supported clade comprised of Leptothecata-Filifera III-IV, and a second clade comprised of Aplanulata-Capitata s.s.-Filifera I-II. Finally, we describe our relatively inexpensive and accessible multiplexing strategy to sequence long-range PCR amplicons that can be adapted to most high-throughput sequencing platforms. 


\section{Introduction}

Cnidaria (corals, anemones, jellyfish, hydroids) is a phylum of relatively simple aquatic animals characterized by the presence of a specific cell type, the cnidocyte, which harbors a highly specialized cellular organelle, the cnidocyst. Cnidaria encompasses five recognized classes (Daly et al., 2007): Anthozoa (stony corals, sea anemones, tube anemones, soft corals and gorgonians), Cubozoa (box jellyfish), Hydrozoa (hydroids, hydromedusae and siphonophores), Scyphozoa (the so-called true jellyfish), and Staurozoa (stalked jellyfish). Nonanthozoan cnidarians are united in the clade Medusozoa (Collins, 2002), whose members typically display a metagenetic life cycle consisting of planula larva, sessile polyp and free-swimming medusa, not all of which may be present in the life cycle of a given species. Within Medusozoa, Hydrozoa represents, to many measures, the most diverse class. Hydrozoa encompasses over $90 \%$ of medusozoan species (Daly et al., 2007), and so it is perhaps unsurprising that life cycle variation, as well as disparity of medusae, polyps, and colonies within this class far exceeds what is observed within Cubozoa, Scyphozoa or Staurozoa. An important and necessary step in understanding the evolution of the remarkable biodiversity present within Hydrozoa is a robust hypothesis of the phylogenetic relationships among its component taxa.

Recent work based on nuclear ribosomal sequences (Collins, 2002; Collins et al., 2006, 2008; Cartwright et al., 2008) and complete mitochondrial genome sequences (Kayal et al., 2013) shows that Hydrozoa consists of two main clades, Trachylina and Hydroidolina. Monophyly of the latter is also supported by phylogenetic analyses of life history and anatomical features (Marques \& Collins, 2004). Trachylina is relatively poor in terms of species richness, containing roughly 150 species in four orders: Limnomedusae, Trachymedusae, Narcomedusae and Actinulida (Collins et al., 2008). The remainder of the approximately 3,350 species of hydrozoans (Daly et al., 2007) that make up the clade Hydroidolina, are classified in three orders: Anthoathecata, Leptothecata and Siphonophora ( Schuchert, P. (2015). Hydroidolina. Accessed through: Schuchert, P. (2015) World Hydrozoa database at http://www.marinespecies.org/hydrozoa/aphia.php?p=taxdetails\&id=19494 on 2015-07-09). Hydroidolina comprises almost all hydrozoans whose life cycle includes a benthic polypoid or hydroid stage (the exception being Limnomedusae, which is part of Trachylina). Colonial hydroid stages within Hydroidolina, especially siphonophores, tend to have greater functional specialization between zooids than other colonial members of Cnidaria (Hyman, 1940; Dunn, Pugh \& Haddock, 2005; Dunn, 2009; Cartwright \& Nawrocki, 2010). 
Siphonophorae) have strong support for their monophyly: Leptothecata whose constituent species' hydroid phase contains a theca (with a few exceptions) and whose medusae (when present) have gonads along the radial canals (Cartwright et al., 2008; Leclère et al., 2009), and Siphonophorae, pelagic animals with a remarkable level of colony organization (Dunn, Pugh \& Haddock, 2005; Cartwright et al., 2008; Dunn, 2009). In contrast, no phylogenetic analysis has provided support for the monophyly of Anthoathecata. Anthoathecata contains those species that lack a theca during the hydroid phase and whose medusae (when present) usually bear gonads on the manubrium (Cartwright et al., 2008). Yet, the absence of thecae can easily be interpreted as plesiomorphic (Cartwright \& Nawrocki, 2010). Even though there has been no support for the monophyly of Anthoathecata, several likely clades have been identified within this taxonomic group Aplanulata, a group consisting of hydrozoans that lack a ciliated planula stage was introduced recently (Collins et al., 2005) and its monophyly supported in subsequent studies

(Collins et al., 2006; Cartwright et al., 2008; Kayal et al., 2013; Nawrocki et al., 2013). Aplanulata contains a portion of the families whose species, in the hydroid stage, possess capitate tentacles. In the past, all hydrozoan species possessing capitate tentacles have been united within the anthoathecate suborder Capitata. However, the taxon has become restricted to a well-supported clade of non-Aplanulata species with capitate tentacles (Collins et al., 2005; Nawrocki, Schuchert \& Cartwright, 2010), referred to as Capitata sensu stricto by Cartwright et al. (2008). The status of the anthoathecate suborder Filifera, containing species whose hydroid stage has tentacles with more or less uniform distribution of nematocysts (filiform), is even more complex, with no less than four putative clades with various levels of support recognized (Cartwright et al., 2008; Cartwright \& Nawrocki, 2010).

Despite the recognition of several possible and likely clades within Hydroidolina, phylogenetic analyses have thus far suffered from low support for deep nodes representing the relationships among them. Filifera has never been recovered as a monophyletic group in any explicit phylogenetic analysis, nor has there been support for relationships among the filiferan clades, Capitata, Aplanulata, Leptothecata and Siphonophora (Collins, 2002; Collins et al., 2006, 2008; Cartwright et al., 2008; Cartwright \& Nawrocki, 2010). Lack of resolution among the deep nodes of Hydroidolina hinders our understanding of their evolution. Indeed, a recent review (Cartwright \& Nawrocki, 2010) highlighted the complexity of morphological characters in the evolutionary history of Hydrozoa and lamented the current lack of resolution of hydroidolinan phylogeny, particularly at ordinal and subordinal levels, which prevents a better understanding of life cycle evolution within this class. 
91

Recent technological advances have allowed us to target the nearly complete mtDNA instead of the singlelocus approaches, including barcoding, often used in systematics and biodiversity studies (Dettai et al., 2012). The small size and circular nature of the majority of animal mtDNAs make them accessible for low-budget taxonomic studies, given the availability of simple and inexpensive protocols. It is now possible to amplify the complete mtDNA using long-range PCR (Burger et al., 2007), which combined with novel high-throughput sequencing technologies, provide access to mitogenomic data for groups considered "difficult-to-sequence" at very low cost and effort (Kayal et al., 2012; Briscoe et al., 2013; Foox et al., 2015). To date, the mtDNA of 188 non-bilaterian animals has been sequenced, out of which 124 are cnidarians, mostly anthozoans.

Medusozoan mtDNA sequencing presents a unique challenge in that all medusozoans possess linear mitochondrial genomes (Kayal et al., 2012). Sequencing complete linear chromosomes using traditional long-PCR approach requires knowledge of genome organization, particularly the genes at the ends of the linear molecules. Specifically, studies have suggested that the mitochondrial genome in medusozoan cnidarians can be mono-, bi-, or octo-chromosomal (Ender \& Schierwater, 2003; Voigt, Erpenbeck \& Wörheide, 2008; Kayal \& Lavrov, 2008; Park et al., 2012; Zou et al., 2012; Kayal et al., 2012; Smith et al., 2012). Interestingly, the linearization of medusozoan mtDNA appears to coincide with relative stability in the gene organization of most medusozoans (Kayal et al., 2012), which facilitates designing protocols for amplification and sequencing most of the coding regions of the mitochondrial chromosome(s).

We present an analysis of nearly-complete mitochondrial genome sequences from a diverse set of hydrozoan taxa in an effort to better understand the relationships within Hydroidolina. Specifically, we describe twenty-six novel, nearly-complete mitochondrial genomes from several hydrozoan orders. We first analyzed the composition and gene order of these mitochondrial genomes. We then used RNA-seq data to infer some of the mechanisms involved in mitochondrial gene expression. Finally, we used both the nucleotide and amino acid sequence data to reconstruct the evolutionary history of hydrozoans, focusing on the thus far intractable relationships within Hydroidolina. 


\section{Material and methods}

\section{Taxon sampling}

We sampled species from both hydrozoan subclasses, Trachylina (three species) and Hydroidolina (twentythree species), maximizing the coverage of hydrozoan diversity by sampling at least one species from all the currently recognized hydroidolinan clades that correspond to the orders/suborders Aplanulata, Capitata s.s., Filifera I-IV, Leptothecata, Siphonophorae (Table 1). We acquired all publicly available medusozoan mitochondrial genomes through Genbank, including nineteen non-hydrozoans used as outgroup taxa (Table 1).

\section{Obtaining nearly-complete mitochondrial genomes}

We followed the protocol described in a previous study (Kayal et al., 2012) to amplify the nearly-complete mitochondrial DNA (mtDNA) of sixteen hydrozoan species. This protocol exploits the relative conservation of the gene organization within Hydrozoa to amplify the nearly-complete mtDNA in one or two pieces via long-range PCR. First, we used conserved metazoan primers to amplify and sequence regions of coxl and rns genes in all sampled taxa. For the two species of Trachylina, we also amplified and sequenced regions of $c o b$ and $r n l$. Finally, for several species rns was difficult to amplify and we sequenced nad5 instead. We then designed species-specific and conserved primers for long-range PCR amplification as described in Kayal et al. (Kayal et al., 2012). We amplified the nearly complete mtDNA (encompassing most coding regions) in one or two contigs using Ranger Taq (Bioline) with a combination of one, two or three sets of primers (see Table S1 for the list of primers and lengths of long PCR amplificons per species). Long amplicons were visualized on an Agarose gel, when necessary multiple amplicons were pooled for each individual specimen, and sheared to the appropriate size-range using a Q800R sonicator (QSONICA). Sheared amplicons were processed for multiplexed double-tagged library preparation for Illumina (100 bp single-end) or Ion Torrent (200 bp single-end) sequencing using custom protocols (see Supplementary information for detailed protocols). Sequencing was performed either on one lane of Illumina HiSeq2000 platform (Illumina) at the Genomics Core Lab of the University of Alabama or using one $316 \mathrm{v} .1$ chip on the Ion Torrent Personal Genome Machine Ion platform (PGM, Life Technologies) at the Laboratories of Analytical Biology of the Smithsonian National Museum of Natural History. 
142

143

144

145

146

147

148

149

Sequence reads were sorted per taxon by index and barcode using the Galaxy Barcode Splitter from the Galaxy platform (Giardine et al., 2005; Blankenberg et al., 2010; Goecks, Nekrutenko \& Taylor, 2010) and Geneious v.7 (Kearse et al., 2012), respectively. Reads were trimmed and the barcode removed using Geneious before proceeding to assembly using the built-in overlap-layout-consensus assembler of Geneious v.7 and a modified version of MITObim v.1.7 (Hahn, Bachmann \& Chevreux, 2013). Then, we used these consensus sequences as backbones to map the sorted and end-trimmed raw reads using both MIRA v.4 (Chevreux, Wetter \& Suhai, 1999) and the built-in Geneious mapping plug-in. The final contigs covered the nearly complete mtDNAs as expected from long-range PCR amplifications.

We also probed several large sequence libraries: DNA-seq libraries obtained from a specimen of Liriope tetraphylla and two non-clonal specimens of Cladonema pacificum; RNA-seq (EST) libraries obtained from the siphonophores Nanomia bijuga and Physalia physalis, Craspedacusta sowerbyi, Ectopleura larynx, Podocoryna carnea and two species of Hydractinia, H. polyclina and H. symbiolongicarpus (Table 1). For these specimens, we first captured several mitochondrial regions by mapping raw reads to the mtDNA from other hydrozoan genomes with Bowtie v.2 (Langmead \& Salzberg, 2012) and MIRA v.4. We then extended these contigs with several rounds of baiting (using the mirabait script from MIRA v.4) and assembly (using the overlap-layout consensus assembler in Geneious) into gapped mtDNAs for E. larynx, C. sowerbyi, L. tetraphylla, P. carnea, H. polyclina, $H$. symbiolongicarpus, one specimen of $P$. physalis and C. pacificum, as well as the nearly-complete coding regions for N. bijuga, and another specimen of $P$. physalis.

We identified protein genes by blasting large (>300 bp) open reading frames (ORFs) obtained via translation using the minimally derived genetic code (translation table $4=$ the Mold, Protozoan, and Coelenterate Mitochondrial Code) against published hydrozoan mtDNA genomes, followed by manual annotation. Transfer RNA (tRNA) genes were identified using the tRNAscan-SE and ARWEN programs (Lowe \& Eddy, 1997; Laslett \& Canbäck, 2008). We identified ribosomal (rRNA) genes by similarity (BLAST searches on NCBI's GenBank) to their counterparts in published mt-genomes and delimited the ends by alignment (see below). 

(Kayal et al., 2013). In short, the amino acid (AA hereafter) sequences of protein-coding genes were individually aligned using the L-INS-i option with default parameters of the MAFFT v.7 aligner online (Katoh \& Standley, 2013) and subsequently concatenated. Nucleotide (NT hereafter) alignments for individual protein-coding genes were obtained according to their AA alignments using the online version of the PAL2NAL online program (Suyama, Torrents \& Bork, 2006) and subsequently concatenated. Ribosomal genes (rRNA hereafter) were individually aligned using the online version of MAFFT with the Q-INS-i option (Katoh \& Toh, 2008) and concatenated. We also created a concatenated all-nucleotides dataset consisting of NT and rRNA alignments (allNT hereafter). All concatenated alignments were filtered using Gblocks (Talavera \& Castresana, 2007) with default parameters, allowing gaps in all positions, leading to alignments with 2902 positions (2501 informative sites) for AA, 9864 positions (8850 informative sites) for NT, 2154 positions (1664 informative sites) for rRNA, and 12018 positions (10773 informative sites) for allNT (Table S3, all alignments are provided as Supplementary information). We estimated the number of phylogenetically informative sites with the DIVEIN online server (Deng et al., 2010), and the saturation levels of nucleotide alignments (NT, rRNA and allNT) using the DAMBE5 software (Xia, 2013). We performed jModelTest v.2.1.4 (Darriba et al., 2012) and ProtTest v.3 (Darriba et al., 2011) on the nucleotide and amino acid alignments, respectively, to identify the most appropriate models of sequence evolution across entire alignments for subsequent phylogenetic analyses. Phylogenetic inferences were conducted under Maximum Likelihood framework using RAxML v.8 (Stamatakis, 2014) and under Bayesian framework using MrBayes v.3.2.2 (Ronquist et al., 2012). Maximum Likelihood analyses were performed using the LG model of sequence evolution for amino acids. The General Time Reversible (GTR) models of nucleotide and amino acid evolution for all alignments were used for both Maximum Likelihood and Bayesian. Bayesian analyses consisted of two runs of 4 chains each of 10,000,000 generations using the GTR model for all alignments, sampled every 100 trees after a burn-in fraction of 0.25 . 
dimensional plots using the first two principal components as calculated by the princomp function in $\mathrm{R}$ version 2.15.1 (Team, 2014).

\section{Evaluation of competing phylogenetic hypotheses}

We tested 3 sets of traditional hypotheses of hydroidolinan relationships using likelihood-based topology tests with the approximately unbiased (AU) tests as implemented in Consel (Shimodaira \& Hasegawa, 2001). Phylogenetic analyses were performed under the three following scenarios using constrained topological ML searches in PhyML v. 3.1 (Guindon et al., 2010) to calculate per-site likelihoods.

1) Several studies have found Capitata to be the earliest branching clade within Hydroidolina ( e.g. Collins, 2002; Marques \& Collins, 2004; Cartwright et al., 2008; Cartwright \& Nawrocki, 2010) while another study suggested Aplanulata to be the earliest branch within Hydroidolina (Collins et al., 2006). We compared these hypotheses to our best tree to evaluate if our data were able to reject either of these alternatives. 2) Filifera was traditionally viewed as being a monophyletic clade, but support for this nominal taxon has not been found so far (reviewed in Collins, 2009). We calculated the best ML tree under the constraint of the monophyly of Filifera and compared the resulting per-site likelihoods to those calculated from our best tree to evaluate if we can reject Filifera's monophyly given our datasets. 3) Anthoathecata (Aplanulata + Capitata) is a traditional taxon within Hydroidolina, a group not supported by our study and others (Collins, 2009); we compared the constrained topology containing monophyletic Anthoathecata to our best tree. 
210

\section{Results}

The mitochondrial genomes of hydrozoan cnidarians

We obtained partial or complete mtDNA from twenty-six hydrozoan species, more than tripling the number of mitogenomes available to date for this class. We found four different genome organizations in these hydrozoans (Fig. 1), three of which were described previously (Kayal et al., 2012): the trachymedusae Geryonia proboscidalis and Liriope tetraphylla have a mitochondrial genome organization similar to that known from other trachylines, Cubaia aphrodite (Kayal et al., 2012) and Craspedacusta sowerbyi (Zou et al., 2012); the $\mathrm{mt}$ genome organization in the aplanulatan Euphysa aurata is similar to those of other members of Aplanulata, Ectopleura larynx and Hydra oligactis (Fig. 1, Kayal et al., 2012); the mt-genome organization in the species Catablema vesicarium, Cladonema pacificum, Craseoa lathetica, Eudendrium capilare, Halitholus cirratus, Hydractinia polyclina, $H$. symbiolongicarpus, Leuckartiara octona, Melicertum octocostatum, Mitrocomella polydiademata, Nanomia bijuga, Podocoryna carnea, Ptychogena lactea, Rathkea octopunctata, Rhizophysa eysenhardti, Sarsia tubulosa, and Tiaropsis multicirrata, as well as the partial mitogenome of Proboscidactyla flavicirrata are all similar to that of non-aplanulatan hydroidolinans described previously (Kayal et al., 2012). The mtDNA sequences of Boreohydra simplex and Plotocnide borealis were identical, confirming previous suggestions that these two names represent two stages in the life cycle of the same species (Pyataeva et al. accepted pending minor revision). Interestingly, the mt genome organization of this species is novel, potentially representing a transitional state between the mtDNA organization of other aplanulatan and that of non-aplanulatan hydroidolinans (Fig. 1, see Discussion).

We analyzed a large dataset of RNA-seq data ( $>230$ M reads) from the siphonophore Physalia physalis and assembled the nearly-complete $\mathrm{mt}$ genome in multiple contigs. The mitochondrial genes represented only $>7,000$ reads $(<0.003 \%$ of the total number of reads) of the Physalia RNA-seq data. We found both small and large ribosomal RNA subunits ( $r n s$ and $r n l$, respectively) as well as the protein genes cob, coxl, and cox2 in single-gene contigs. The other protein genes were found in collinear contigs as follows: atp8-atp6-cox3, nad2-nad5, and nad6nad3-nad4L-nad1-nad4 (Fig. 2A). We were not able to identify with enough confidence the two expected tRNA genes $m t-t R N A-M e t$ and $m t-t R N A-T h r$ in this large RNA-seq dataset. Using an independently generated, smaller source of RNA-seq data (SRA Archive num. SRR871528), we assembled a more complete mt genome, confirming that the mtDNA organization in Physalia physalis was similar to that of the other siphonophore Rhizophysa 
eysenhardti obtained through long-range PCR. This smaller RNA-seq dataset provided the nearly-complete mtDNA sequence, with a few scattered gaps. The low amount of sequence data for Nanomia bijuga did not allow us to identify all the protein genes.

Genes were found to be very similar in length among all species (varying from identical to about $5 \%$ different in length). We found the GC content to be variable among the hydrozoan species we sampled, ranging $13.1-46.9 \%$ for protein coding genes, $19.4-39.1 \%$ for rRNA genes and $22.9-47.9 \%$ for tRNA genes. The most commonly used start codon was ATG except for atp8 in Boreohydra simplex/Plotocnide borealis (TTG) and Tiaropsis multicirrata (GTG); cob in Tiaropsis multicirrata (TTG); coxl in Euphysa aurata (GTG); nad1 in Physalia physalis (GTG); nad2 in Catablema vesicarium, Halitholus cirratus, and Nanomia bijuga (GTG); nad3 in Physalia physalis (GTG); nad4 in Ptychogena lactea (GTG); nad4L in Nanomia bijuga (GTG); nad5 in Boreohydra simplex/Plotocnide borealis (TTG); nad6 in Catablema vesicarium and Nanomia bijuga (GTG). TAA was the most commonly used stop codon for protein genes, with the exception of nad5 and nad 6 where TAG was most often used (Table 2).

Phylomitogenomics of Hydrozoa

Our AA, NT, rRNA, and allNT analyses under both Maximum Likelihood and Bayesian frameworks did not yield completely consistent results (Fig. 3, S1-S8). Under GTR, the AA (Fig. S1, S5), NT (Fig. S2, S6) and allNT (Fig. 3, S4) Maximum Likelihood and Bayesian analyses, respectively, yielded almost identical topologies, whereas the rRNA-based topologies (Fig. S3, S7) and the AA topology assuming the LG model (Fig. S8) exhibited far lower resolution and support than all other topologies. The PCA of amino acid and nucleotide compositions (Fig. 4) of the alignments underlying our phylogenetic analyses, where taxa with similar composition cluster together, do not show evidence of strong compositional biases that may affect phylogenetic reconstruction.

Overall, we found a number of common relationships in all phylogenetic trees that were highly supported: the divergence between Trachylina and Hydroidolina within Hydrozoa, the monophyly of Leptothecata, Capitata s.s. and Aplanulata (Table 3). Within Hydroidolina, all analyses other than those based on just the rRNA data alone: 1) identified siphonophores as the first diverging clade in most trees; 2) supported Filifera I + Filifera II; 3) supported Aplanulata + Capitata s.s. + Filifera I-II; 4) supported Filifera III + Filifera IV, with the latter being paraphyletic 
263 with respect to the former in many trees, and; 5) supported Leptothecata + Filifera III-IV (Table 3). No analyses

264 recovered Capitata in its former sense [Aplanaluta + Capitata s.s.] nor the monophyly of Anthoathecata or Filifera.

265 Our constraint analyses show that the placement of Capitata or Aplanulata as the earliest branching clades within

266 Hydroidolina is rejected by both NT and allNT (NT plus rRNA) alignments, whereas both AA and rRNA data alone

267 cannot reject these hypotheses (Table S5). The monophyly of Filifera was rejected in all cases other than for the

268 rRNA dataset (Table S5). Lastly, the monophyly of Anthoathecata was rejected for both NT and allNT datasets

269 while AA and rRNA alignments do not reject this traditional hypothesis (Table S5). 


\section{Discussion}

272

\section{The evolution of mtDNA in Hydrozoa}

The gene arrangements of the newly sequenced hydrozoan mtDNAs are consistent with the three organizations recovered earlier (Kayal et al., 2012). For instance, the new trachyline mtDNAs exhibit the predicted organization of the ancestral mt-genome organization for Hydrozoa, with genes ordered into a small cluster (four genes, including the two extra protein genes polB and orf314) and a large cluster (thirteen genes) with opposite orientations (Kayal et al., 2012). We note, however, that our taxon sampling within Trachylina is still relatively limited, restricted to representatives of Limnomedusae plus the Trachymedusae Liriope tetraphylla and Geryonia proboscidalis, which have been shown to be more closely related to Limnomedusae than to other members of Trachymedusae (Collins et al., 2008). Thus, the possibility remains that other trachyline taxa (including Narcomedusae, Actinulida and other members of Trachymedusae) could exhibit an as yet unidentified mt-genome organization. New taxon sampling within Hydroidolina shows that hydroidolinan mtDNA organization is nearly identical to that so far observed in trachylines, except that they lack, and likely lost (Kayal et al., 2012), the two nonstandard protein-coding genes polB and orf314. Gene organizations within Aplanulata are the most derived from the putative ancestral one for Hydroidolina, where all genes are in the same orientation but the second copy of cox 1 (which can be partial) oriented in the opposite direction to the rest of the genome (Fig. 1). Our new data are partially consistent with the proposed scenario for the evolution of the mitochondrial genome organization in Hydrozoa (Kayal et al., 2012). Specifically, the ancestral hydrozoan mtDNA contained the two extra protein-coding genes $\operatorname{orf3} 14$ and $\mathrm{polB}$, which were subsequently lost in Hydroidolina before the divergence of various orders. Aplanulata displays not two, but three increasingly derived genome organizations generated by sequential gene rearrangement (Fig. 1): inversion of $r n l$ and translocation of $t r n W$ in Boreohydra simplex/Plotocnide borealis; translocation of trnM in Ectopleura larynx, Euphysa aurata and Hydra oligactis; partitioning of the genome into two nearly equal-sized chromosomes in some species of Hydra (Kayal et al., 2012). We found inter-genic regions (IGRs) longer than $10 \mathrm{bp}$ found after cox2 in Boreohydra simplex/Plotocnide borealis and after cox3 in Ectopleura larynx, Euphysa aurata and Hydra spp. These IGRs could conceivably be residues left from the translocations of trnW and trnM, respectively, but no obvious homology was found in our alignments (data not shown). 
In Metazoa, mitochondrial gene expression is thought to follow the "tRNA punctuation model", where mt

299

300

301

302

303

304

genes are transcribed into polycistronic precursor transcripts (Ojala, Montoya \& Attardi, 1981; Gissi \& Pesole, 2003), followed by the excision of the tRNAs that release single-gene (monocistronic) mRNAs and rRNAs (Mercer et al., 2011). Unlike most animals, cnidarian mtDNAs encode either one (trnM in Cubozoa and Octocorallia) or two (trnM and $\operatorname{trn} W$ in the remaining taxa) tRNA genes. This begs the question of the mechanisms involved in the expression of $\mathrm{mt}$ genes for this group.

RNA-seq studies provide unique insights into the expression of genes, and we used data obtained through RNA-sequencing projects to better understand translational mechanisms of the linear mtDNAs in hydrozoans. Surveying several large RNA-seq datasets on NCBI's GenBank and one from an unpublished source (Table 1), we assembled and annotated the nearly complete mtDNA sequences for eight hydroidolinan Hydrozoa species, including three of the first four mtDNA genomes from representatives of Siphonophorae. For all non-aplanulatan hydroidoline hydrozoans species, we found no RNA-seq reads upstream of cox2 and $r n l$, a large intergenic region (IGR) that marks the inversion of the transcriptional orientation of mitochondrial genes (Fig. 1). It was previously suggested that this IGR has the potential to fold into a stem-loop, serving as the putative mt control region (CR) in non-aplanatulan hydroidoline hydrozoans (Kayal et al., 2012); our results further support this hypothesis. In fact, two large RNA-seq runs from the filiferan Hydractinia symbiolongicarpus (SRA Archive num. SRR1174275 and SRR1174698) and one from Podocoryna carnea (SRA Archive num. SRR1796518) allowed assembling the complete mtDNA for these species excluding the $\mathrm{CR}$, with an organization similar to that of other non-aplanulatan hydrozoans. This pattern suggests that the mtDNA is transcribed into two polycistronic precursor transcripts (mt pre-mRNA) with opposite orientations (Fig. 2B). Surprisingly, the CR of Craspedacusta sowerbyi (SRA Archive num. SRR923472) was mapped onto a few RNA-seq reads. We believe that this particular dataset contains some DNA sequences, perhaps resulting from contamination of the original cDNA libraries by mitochondrial DNA.

In siphonophores, as in other non-aplanulatan hydroidolinans, the $\operatorname{trn} W$ gene is situated between $\operatorname{cox} 2$ and atp8, while the trnM gene falls between $\operatorname{cox} 3$ and nad2 (Fig. 1). While we expect the mt genome of the siphonophore Physalia physalis to be organized into a single chromosome similar to that of Rhizophysa eysenhardti as suggested by the small RNA-seq data, the partial mt genome obtained from the large RNA-seq data assembled into eight contigs (Fig. 2A). The smaller RNA-seq dataset produced six contigs, including polycistronic 


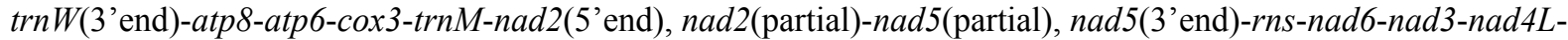
nad1-nad4(partial) and $\operatorname{cob}$ (partial)-coxl, as well as monocystronic cox 2 and $r n l$. The failure to recover full-length genes likely resulted from insufficient coverage of mt-RNAs in this dataset. For the larger RNA-seq dataset, we found a different pattern of gaps, none within genes; reads span across protein gene boundaries for atp8-atp6-cox3, nad2-nad5, and nad6-nad3-nad4L-nad1-nad4 (Fig. 2A) with average coverage ranging from 8-223 reads per contig (data not shown). The absence of any reads between these gene clusters, as well as between contigs nad2-nad5 and rns or rns and nad6-nad3-nad4L-nad1-nad4 in the large RNA-seq data neither appears to be the result of insufficient read depth nor is it easily explained by the highly transient nature of the polycistronic precursor (pre-mRNA) transcript. The two sets of Physalia RNA data were produced using different approaches for capturing ESTs and building the Illumina libraries, resulting in different maturation levels of the transcripts. We posit that the larger RNA-seq dataset contains only mature mt-mRNAs while the smaller RNA-seq dataset has both pre- and mature mRNAs. Accordingly, the pattern of mt-RNA expression is in part in accord with the tRNA punctuation model, where the excision of the tRNAs would release monocistronic cox 2 and polycistronic atp8-atp6-cox3 from the premRNA (Fig 2B, Step 2, black arrows). Yet, this model does not explain the bicistronic nad2-nad5 nor monocistronic $r n s, c o b$ and coxl. It is possible that both the rRNAs and the tRNAs are excised, simultaneously or sequentially, from the precursor transcript, releasing bicistronic nad2-nad5 and monocistronic rns (Fig 2B, Step 2, red arrows). However, an additional mechanism would need to be invoked to explain the excision of $c o b$ and coxl (as illustrated by the absence of reads spanning across that gene boundary) from the polycistronic precursor transcripts. We observed intergenic regions of 10 bp or longer with conserved motifs in these positions (Fig. 2, S9) with potential secondary structures (Fig. S10) that could represent recognition sites for the enzyme involved in maturation of mRNA (Fig. 2B, Step 2, blue arrows). This scenario is supported by the presence of IGRs before (and sometimes after) mt-tRNAs. In fact, by forming short stem-loops, these IGRs might signal for the maturation of mt pre-mRNA in Hydrozoa in a similar fashion as mt-tRNAs in other animals (Mercer et al., 2011).

\section{Mitochondrial view of hydrozoan character evolutionary history}

Using the coding regions of the mtDNA from thirty-seven hydrozoan species, including twenty-six newly obtained for this study, we inferred the evolutionary history of Hydrozoa. To date, most studies of hydrozoan phylogeny have relied on rRNA sequence data, providing some important insights, but no reliable inferences of 
relationships among hydroidolinan taxa (Collins et al., 2006; Cartwright et al., 2008; Cartwright \& Nawrocki, 2010). In our analyses, we similarly found mt-rRNA insufficient for deciphering relationships among hydroidolinan lower clades with high support (Fig. S3, S7; Table 3). The saturation test (Xia et al., 2003) suggests a high level of saturation in the rRNA alignment for 16 and 32 OTUs, while saturation levels are assumed acceptable for the other datasets (Table S2), which could explain the poor performance of rRNA. Similarly, rRNA alone did not allow discriminating among several competing hypotheses of hydroidolinan relationships while NT data did (Table S5).

Our phylogenetic analyses strongly support the monophyly of Trachylina and Hydroidolina, while rejecting Anthoathecata and Filifera as suggested by other molecular data (Cartwright et al., 2008; Cartwright \& Nawrocki, 2010). Interestingly, our data support the hypothesis that Siphonophorae is the first diverging lineage within Hydroidolina (Fig. 3, Table 3) in contrast to a recent phylogenomic study that found Aplanulata to be the earliest branching clade within Hydroidolina while Siphonophorae was nested within Hydroidolina (Zapata et al., 2015). Previous studies have grouped, though with low support, Siphonophorae with either Aplanulata (Cartwright et al., 2008) or Leptothecata (Cartwright et al., 2008; Cartwright \& Nawrocki, 2010), but both hypothetical positions are contradicted by our analyses (Table 3). Our competing hypothesis suggests that the unique holopelagic colonial organization of siphonophores could have been an early innovation within Hydrozoa. However, given that it is apomorphic, it could have evolved anywhere along the lineage leading from the origin of Hydroidolina to the last common ancestor of Siphonophorae.

Recent rRNA phylogenetic studies have broken Filifera into four clades (I-IV), with varying levels of support (Cartwright et al., 2008). As with our data, rRNA data revealed a clade, albeit with low support, uniting Filifera I (=family Eudendriidae), Filifera II, and Aplanulata. Similarly, our results are consistent with the rRNAbased results, again with low support, that Filifera III and Filifera IV form a clade. However, mitochondrial genome data suggest that Filifera III is embedded within Filifera IV. Studies on morphology and rRNA data have placed Clava multicornis within Hydractiniidae, making it a member of Filifera III (Schuchert, 2001; Cartwright et al., 2008), which is confirmed by our results. Interestingly, in our trees Filifera IV was found to include a poorly supported, but morphologically distinct, clade dubbed Gonoproxima, containing species that do not bear gonophores on the hydranth body instead budding on the hydrocauli, pedicels, or stolons (Cartwright et al., 2008; Cartwright \& Nawrocki, 2010). Our taxon sampling is much more depauperate, but our analyses suggest that the positioning of the 
gonophores may perhaps be evolutionarily too labile to be strictly used for classification, similar to the presence of scattered tentacles (Schuchert, 2001).

The well-supported clade formed by [Aplanulata $+[$ Filifera I + II] + Capitata $]$ is an interesting result, but our taxon sampling is too limited to make strong conclusions about whether the capitate tentacles of Aplanulata and Capitata are shared derived characters (with a reversal in the lineage leading to Filifera I + Filifera II), or whether they evolved independently. It is not surprising that the absence of capitate tentacles (the main uniting feature of Filifera) is not revealed to be a synapomorphy.

Significantly more than half of the species within Hydroidolina are contained within Leptothecata, which highlights the lack of taxon sampling in our analysis with just five species represented. Ribosomal analyses have revealed Melicertum octocostatum, a species that actually lacks a theca in the hydroid stage, to be of the sister taxon to the remainder of Leptothecata (Cartwright et al., 2008; Leclère et al., 2009; Cartwright \& Nawrocki, 2010), raising the possibility that the theca was derived within Leptothecata rather than emerging right at its base. Our analyses also contain Melicertum octocostatum diverging early within Leptothecata, but not sister to all other sampled leptothecates. Given the caveat that taxon sampling is limited, the absence of a theca in Melicertum is likely a secondary loss. In fact, several other leptothecates show a reduced or diminutive theca into which the hydranth is not able to retract.

\section{Conclusion}

In this study, we assembled and annotated twenty-three novel nearly-complete or complete mitochondrial genomes from most orders of the class Hydrozoa, with an emphasis on the subclass Hydroidolina. Increased taxon sampling revealed only one additional mitogenome organizations than those described previously for hydrozoans, being consistent with the most recent overall picture of mitogenome evolution (Kayal et al., 2012). Using EST data, we proposed that the mitochondrial pre-mRNA is polycistronic, with tRNAs and rRNAs likely excised simultaneously during transcription following a modified tRNA punctuation model. Using both nucleotide and amino acid alignments, we inferred the evolutionary history of taxa within Hydroidolina, one of the most difficult questions in cnidarian phylogenetics. In contrast to previous analyses, our data yield resolved topologies and provide a working hypothesis for deep hydroidolinan relationships. Specifically, mitogenome data suggest that 
405 Siphonophorae is the earliest diverging group within Hydroidolina; a clade is formed by Leptothecata + Filifera 406 III/IV, where Filifera IV/Gonoproxima is paraphyletic; and Aplanulata/Capitata/Filifera I + II form a clade. We 407 conclude that mitochondrial protein coding sequence data is a pertinent marker for resolving the phylogeny of 408 Hydrozoa. Future investigations of hydrozoans could take advantage of the highly conserved mitogenome 409 organization and the ever-decreasing price of sequencing to obtain the complete mtDNA for massive numbers of

410 hydrozoan samples. We are looking forward to additional studies using alternate data (nuclear genes and genomes)

411 to test our findings. 


\section{Acknowledgements}

414 We would like to thank Matthew Kwenskin for his help with installing and modifying the bioinformatics

415 tools and Niamh Redmond for assistance developing the library preparation protocol. Much of this work was

416 performed using resources of the Laboratories of Analytical Biology at the Smithsonian National Museum of

417 Natural History. Peter Schuchert is gratefully acknowledged for providing specimens/DNA extracts and for

418 providing feedback on an earlier version of this MS.

419 


\section{References}

Blankenberg D, Von Kuster G, Coraor N, Ananda G, Lazarus R, Mangan M, Nekrutenko A, Taylor J. 2010. Galaxy: a web-based genome analysis tool for experimentalists. Current protocols in molecular biology / edited by Frederick M. Ausubel ... [et al.] Chapter 19:Unit 19.10.1-19.10.21.

Briscoe AG, Goodacre S, Masta SE, Taylor MI, Arnedo MA, Penney D, Kenny J, Creer S. 2013. Can long-range PCR be used to amplify genetically divergent mitochondrial genomes for comparative phylogenetics? A case study within spiders (Arthropoda: Araneae). PloS ONE 8:e62404.

Burger G, Lavrov D V, Forget L, Lang FB. 2007. Sequencing complete mitochondrial and plastid genomes. Nature protocols 2:603-14.

Cartwright P, Evans NM, Dunn CW, Marques AC, Miglietta MP, Schuchert P, Collins AG. 2008. Phylogenetics of Hydroidolina (Hydrozoa: Cnidaria). Journal of the Marine Biological Association of the United Kingdom 88:1663-1672.

Cartwright P, Nawrocki AM. 2010. Character Evolution in Hydrozoa (phylum Cnidaria). Integrative and Comparative Biology 50:456-472.

Chevreux B, Wetter T, Suhai S. 1999. Genome Sequence Assembly Using Trace Signals and Additional Sequence Information. Computer Science and Biology: Proceedings of the German Conference on Bioinformatics (GCB) 99:45-56.

Collins AG. 2002. Phylogeny of Medusozoa and the evolution of cnidarian life cycles. Journal of Evolutionary Biology 15:418-432.

Collins AG, Winkelmann S, Hadrys H, Schierwater B. 2005. Phylogeny of Capitata and Corynidae (Cnidaria, Hydrozoa) in light of mitochondrial 16S rDNA data. Zoologica Scripta 34:91-99.

Collins AG, Schuchert P, Marques AC, Jankowski T, Medina M, Schierwater B. 2006. Medusozoan phylogeny and character evolution clarified by new large and small subunit rDNA data and an assessment of the utility of phylogenetic mixture models. Systematic biology 55:97-115.

Collins AG, Bentlage B, Lindner A, Lindsay D, Haddock SHD, Jarms G, Norenburg JL, Jankowski T, Cartwright P. 2008. Phylogenetics of Trachylina (Cnidaria: Hydrozoa) with new insights on the evolution of some problematical taxa. Journal of the Marine Biological Association of the United Kingdom 88:1673-1685.

Collins AG. 2009. Recent Insights into Cnidarian Phylogeny. Smithsonian Contributions to Marine Sciences 38:139-149.

Daly M, Brugler MR, Cartwright P, Collins AG, Dawson MN, Fautin DG, France SC, Mcfadden CS, Opresko DM, Rodriguez E, Romano SL, Stake JL. 2007. The phylum Cnidaria: A review of phylogenetic patterns and diversity 300 years after Linnaeus*. Zootaxa 182:127-128.

Darriba D, Taboada GL, Doallo R, Posada D. 2011. ProtTest 3: fast selection of best-fit models of protein evolution. Bioinformatics 27:1164-1165.

Darriba D, Taboada GL, Doallo R, Posada D. 2012. jModelTest 2: more models, new heuristics and parallel computing. Nature Methods 9:772. 
Deng W, Maust BS, Nickle DC, Learn GH, Liu Y, Heath L, Pond SLK, Mullins JI, Kosakovsky Pond SL, Mullins JI. 2010. DIVEIN: A web server to analyze phylogenies, sequence divergence, diversity, and informative sites. BioTechniques 48:405-408.

Dettai A, Gallut C, Brouillet S, Pothier J, Lecointre G, Debruyne R. 2012. Conveniently pre-tagged and prepackaged: extended molecular identification and metagenomics using complete metazoan mitochondrial genomes. PloS one 7:e51263.

Dunham JP, Friesen ML. 2013. A Cost-Effective Method for High-Throughput Construction of Illumina Sequencing Libraries. Cold Spring Harbor Protocols:820-834.

Dunn CW. 2009. Quick guide Siphonophores Essay Binding reactions: epigenetic switches, signal transduction and cancer. Current Biology 19:233-234.

Dunn CW, Pugh PR, Haddock SHD. 2005. Molecular phylogenetics of the siphonophora (Cnidaria), with implications for the evolution of functional specialization. Systematic Biology 54:916-935.

Ender A, Schierwater B. 2003. Placozoa Are Not Derived Cnidarians: Evidence from Molecular Morphology. Molecular Biology and Evolution 20:130-134.

Foox J, Brugler M, Siddall ME, Rodríguez E. 2015. Multiplexed pyrosequencing of nine sea anemone (Cnidaria: Anthozoa: Hexacorallia: Actiniaria) mitochondrial genomes. Mitochondrial DNA 1736:1-7.

Giardine B, Riemer C, Hardison RC, Burhans R, Elnitski L, Shah P, Zhang Y, Blankenberg D, Albert I, Taylor J, Miller W, Kent WJ, Nekrutenko A. 2005. Galaxy: a platform for interactive large-scale genome analysis. Genome Research 15:1451-1455.

Gissi C, Pesole G. 2003. Transcript mapping and genome annotation of ascidian mtDNA using EST data. Genome Research 13:2203-2212.

Goecks J, Nekrutenko A, Taylor J. 2010. Galaxy: a comprehensive approach for supporting accessible, reproducible, and transparent computational research in the life sciences. Genome Biology 11:R86.

Guindon S, Dufayard J-FF, Lefort V, Anisimova M, Hordijk W, Gascuel O. 2010. New algorithms and methods to estimate maximum-likelihood phylogenies: Assessing the performance of PhyML 3.0. Systematic Biology 59:307-321.

Hahn C, Bachmann L, Chevreux B. 2013. Reconstructing mitochondrial genomes directly from genomic nextgeneration sequencing reads--a baiting and iterative mapping approach. Nucleic Acids Research 41:e129.

Hyman LH. 1940. The Invertebrates, Volume 1. Protozoa through Ctenophora. New York: McGraw-Hill Book Company.

Katoh K, Standley DM. 2013. MAFFT multiple sequence alignment software version 7: improvements in performance and usability. Molecular Biology and Evolution 30:772-780.

Katoh K, Toh H. 2008. Recent developments in the MAFFT multiple sequence alignment program. Briefings in Bioinformatics 9:286-298.

Kayal E, Bentlage B, Collins AG, Kayal M, Pirro S, Lavrov D V. 2012. Evolution of linear mitochondrial genomes in medusozoan cnidarians. Genome Biology and Evolution 4:1-12. 
492

Kayal E, Roure B, Philippe H, Collins AG, Lavrov D V. 2013. Cnidarian phylogenetic relationships as revealed by mitogenomics. BMC Evolutionary Biology 13:5.

Kayal E, Lavrov D V. 2008. The mitochondrial genome of Hydra oligactis (Cnidaria, Hydrozoa) sheds new light on animal mtDNA evolution and cnidarian phylogeny. Gene 410:177-186.

Kearse M, Moir R, Wilson A, Stones-Havas S, Cheung M, Sturrock S, Buxton S, Cooper A, Markowitz S, Duran C, Thierer T, Ashton B, Meintjes P, Drummond A. 2012. Geneious Basic: An integrated and extendable desktop software platform for the organization and analysis of sequence data. Bioinformatics 28:1647-1649.

Langmead B, Salzberg SL. 2012. Fast gapped-read alignment with Bowtie 2. Nature Methods 9:357-359.

Laslett D, Canbäck B. 2008. ARWEN: a program to detect tRNA genes in metazoan mitochondrial nucleotide sequences. Bioinformatics (Oxford, England) 24:172-5.

Leclère L, Schuchert P, Cruaud C, Couloux A, Manuel M. 2009. Molecular phylogenetics of Thecata (Hydrozoa, Cnidaria) reveals long-term maintenance of life history traits despite high frequency of recent character changes. Systematic Biology 58:509-26.

Lowe TM, Eddy SR. 1997. tRNAscan-SE: a program for improved detection of transfer RNA genes in genomic sequence. Nucleic Acids Research 25:955-964.

Marques AC, Collins AG. 2004. Cladistic analysis of Medusozoa and cnidarian evolution. Invertebrate Biology $123: 23-42$.

Mercer TR, Neph S, Dinger ME, Crawford J, Smith MA, Shearwood A-MJ, Haugen E, Bracken CP, Rackham O, Stamatoyannopoulos JA, Filipovska A, Mattick JS. 2011. The human mitochondrial transcriptome. Cell 146:645-658.

Meyer M, Kircher M. 2010. Illumina Sequencing Library Preparation for Highly Multiplexed Target Capture and Sequencing. Cold Spring Harb Protoc. 2010:1-8.

Nawrocki AM, Collins AG, Hirano YM, Schuchert P, Cartwright P. 2013. Phylogenetic placement of Hydra and relationships within Aplanulata (Cnidaria: Hydrozoa). Molecular Phylogenetics and Evolution 67:60-71.

Nawrocki AM, Schuchert P, Cartwright P. 2010. Phylogenetics and evolution of Capitata (Cnidaria: Hydrozoa), and the systematics of Corynidae. Zoologica Scripta 39:290-304.

Ojala D, Montoya J, Attardi G. 1981. tRNA punctuation model of RNA processing in human mitochondria. Nature 290:470-474.

Park E, Hwang D-S, Lee J-S, Song J-I, Seo T-K, Won Y-J. 2012. Estimation of divergence times in cnidarian evolution based on mitochondrial protein-coding genes and the fossil record. Molecular Phylogenetics and Evolution 62:329-345.

Rohland N, Reich D. 2012. Cost-effective, high-throughput DNA sequencing libraries for multiplexed target capture. Genome research.

Ronquist F, Teslenko M, van der Mark P, Ayres DL, Darling A, Höhna S, Larget B, Liu L, Suchard MA, Huelsenbeck JP. 2012. MrBayes 3.2: efficient Bayesian phylogenetic inference and model choice across a large model space. Systematic Biology 61:539-542. 
Schuchert P.Hydroidolina. Accessed through: Schuchert, P. (2015) World Hydrozoa database at http:/www.marinespecies.org/hydrozoa/aphia.php? $\mathrm{p}=$ taxdetails\&id=19494 on 2015-07-09. Available at http://www.marinespecies.org/hydrozoa/aphia.php? $p=$ taxdetails\&id $=19494$

Schuchert P. 2001. Hydroids of Greenland and Iceland (Cnidaria, Hydrozoa). Danish Polar Center.

Shimodaira H, Hasegawa M. 2001. CONSEL: for assessing the confidence of phylogenetic tree selection. Bioinformatics (Oxford, England) 17:1246-1247.

Smith DR, Kayal E, Yanagihara AA, Collins AG, Pirro S, Keeling PJ. 2012. First complete mitochondrial genome sequence from a box jellyfish reveals a highly fragmented, linear architecture and insights into telomere evolution. Genome Biology and Evolution 4:52-58.

Stamatakis A. 2014. RAxML version 8: A tool for phylogenetic analysis and post-analysis of large phylogenies. Bioinformatics 30:1312-1313.

Suyama M, Torrents D, Bork P. 2006. PAL2NAL: robust conversion of protein sequence alignments into the corresponding codon alignments. Nucleic Acids Research 34:W609-W612.

Talavera G, Castresana J. 2007. Improvement of phylogenies after removing divergent and ambiguously aligned blocks from protein sequence alignments. Systematic Biology 56:564-577.

Team RC. 2014. R: a language and environment for statistical computing. Vienna, Austria: R Foundation for Statistical Computing; 2012.

Voigt O, Erpenbeck D, Wörheide G. 2008. A fragmented metazoan organellar genome: the two mitochondrial chromosomes of Hydra magnipapillata. BMC genomics 9:350.

Xia X, Xie Z, Salemi M, Chen L, Wang Y. 2003. An index of substitution saturation and its application. Molecular Phylogenetics and Evolution 26:1-7.

Xia X. 2013. DAMBE5: A comprehensive software package for data analysis in molecular biology and evolution. Molecular Biology and Evolution 30:1720-1728.

Zapata F, Goetz FE, Smith SA, Howison M, Siebert S, Church SH, Sanders SM, Ames CL, McFadden CS, France SC, Daly M, Collins AG, Haddock SH, Dunn CW, Cartwright P. 2015. Phylogenomic analyses support traditional relationships within Cnidaria. PLoS ONE 10:e139068.

Zou H, Zhang J, Li W, Wu S, Wang G. 2012. Mitochondrial Genome of the Freshwater Jellyfish Craspedacusta sowerbyi and Phylogenetics of Medusozoa. PloS ONE 7:e51465. 


\section{Supplementary materials}

560

\section{Suppl. 1: Library preparation for multiplexed second-generation sequencing}

We constructed low-cost multiplexed libraries for the Illumina platform. The Illumina library preparation protocol was derived from two sources (Meyer \& Kircher, 2010; Rohland \& Reich, 2012), is similar to another recently published (Dunham \& Friesen, 2013). While our libraries were designed for 100 bp single-end single-index libraries for Illumina, they can easily be adapted to longer inserts as well as paired-end and double-indexing, by modifying the sonication parameters for DNA shearing and the indexed adapters (see below).

\section{1) DNA shearing and sizing:}

Long PCR amplicons for each specimen were purified using Millipore column and combined at equimolar ratios when necessary, i.e. when the mtDNA was amplified in more than one piece. Although this step is not strictly necessary, it allows for the removal of primer dimers, which can otherwise take up a significant portion of the libraries. Purified long-PCR amplicons were sheared to an average size of $600 \mathrm{bp}$ for Illumina libraries and $200 \mathrm{bp}$ for Ion Torrent libraries with a QSonica Q800R Sonicator (2 min or 3 min at 30\% amplitude with $10 \mathrm{sec}$ on/off for Illumina and Ion Torrent, respectively). The size window of sheared amplicons was verified on an Agarose gel. Sheared DNA was recovered with a homemade Serapure beads suspension (Rohland \& Reich, 2012) and quantified using a BioTek Epoch Microplate Spectrophotometer.

We have found that sizing by a combination of sonication-Agarose gel-spectrophotometer yields satisfying results for library preparation on most platforms and is even preferable to more sophisticated and expensive sizing methods such as enzymatic shearing and use of the BioAnalyzer. They are also far less demanding in materials and therefore more environmentally friendly.

\section{2) Illumina library preparation:}

The library preparation consisted of the combination of several previously published massively parallel sequencing protocols (Meyer \& Kircher, 2010; Rohland \& Reich, 2012) into a double tagging approach: an internal tag attached to the 3'end of the universal adapters (we called barcode) and an external tag as part of the indexed adapter (we called index). This highly increased the number of samples to price ratio, but see below. 

over-hanging $\mathrm{T}$ on the 3 'end of the 3 'half to increase the ligation efficiency (sticky-end ligation). We prepared an adapter mix containing a combination of the 3 'half of a barcoded universal adapter and the 3 'half of the index adapter. Sheared DNAs were blunt-end repaired using the NEB Quick Blunting Kit and A-tailed using Klenow Fragment $\left(3^{\prime} \rightarrow 5^{\prime}\right.$ exo-). Adapter mixes (UniAdp_barco1 \& 2/UniComp_barco1 \& 2 and IndAdp_short/IndCompAdp, Table S4) were ligated to individual samples using T4 Ligase, followed by adapter fillin with Bst polymerase large fragments (barcoding). Adapters were completed by short PCR using a High-Fidelity DNA Polymerase and primers (UniAdp_long and IndAdp_long1 to 20) corresponding to the 5 'half of the adapters with one indexed adapter per two samples (indexing). We quantified each library with Thermo Scientific SYBR Green/ROX qPCR Master Mix and pooled all samples in equimolar ratio.

\section{3) Quadruple tagging protocol for Illumina paired-end sequencing:}

Illumina has recently introduced a double indexing library method, where both adapters (i5 and i7) have indexes. As mentioned above, for paired-end sequencing it is possible to exponentially increase the multiplexing level by introducing a tag at the 3 'end of both Illumina adapters. The library preparation would be similar to the one described above, with the adapter mix consisting of the combination of the $3^{\prime}$ ' half of an i5 adapter and the 3' half of an i7 adapter. This will provide each sample with a combination of two indexes and two barcodes. In that way, it is possible to tag 600 samples with five indexes on i5 and four indexes on i7, six barcodes for i5 adapters and five barcodes for i7 adapters. Such an approach reduces the cost of multiplexing by reducing the number of tags, the main driver of high costs for multiplexed libraries when using standard kits. This approach will be most costeffective for barcoding purposes, where the tags can be included at the 5'end of PCR primers, hence removing the substantial cost and potential errors associated with ligation. 


\section{Figure 1 (on next page)}

Predicted evolution of the mitochondrial genome organization in Hydrozoa (Cnidaria).

Genes are color-coded as follows: green for proteins; red for rRNAs; purple for tRNAs; lightgrey for repeated regions. CR: Control Region corresponding to the inversion of transcription orientation; IR: inverted Repeat; IGR: Inter-Genic Region. AMGO corresponds to the Ancestral Mitochondrial Genome Organization as predicted in Kayal et al. 2013; cox1 c is a duplicated cox1 on the other end of the mtDNA; incomplete 5'end and 3 'end are represented by chevrons on the left and right side of genes, respectively. 


\section{Figure 2 (on next page)}

Mitochondrial gene expression in non-aplanulatan Hydroidolina

A. mtDNA organization in the siphonophore Physalia physalis assembled from a large EST dataset. Grey lines correspond to the contigs assembled. Missing features (tRNAs, IGRs, CR) are shown with dotted lines. B. Predicted model of mt-mRNA expression based on findings from $P$. physalis. Color-codes are the same as Figure 1. Grey horizontal arrows are the two pre-mRNA transcripts, the larger being polycistronic. Dark vertical arrows correspond to regions of pre-mRNA excision from the "tRNA punctuation model"; red and blue arrows are the additional excision sites predicted from our model for hydrozoan mt-mRNA expression. We predict that stage 1 and 2 are simultaneous. 


\section{PeerJ}

Physalia physalis

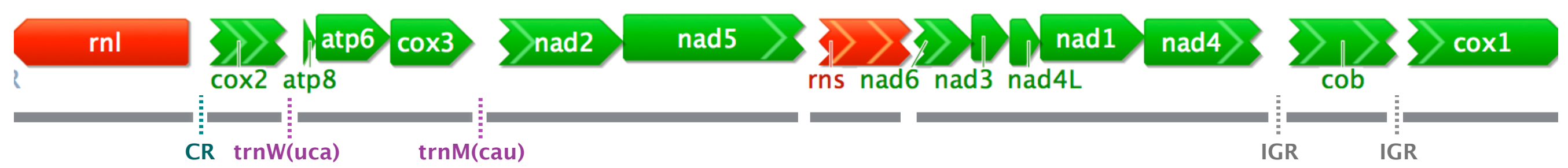

Model of mRNA expression in non-aplanulatan Hydroidolina

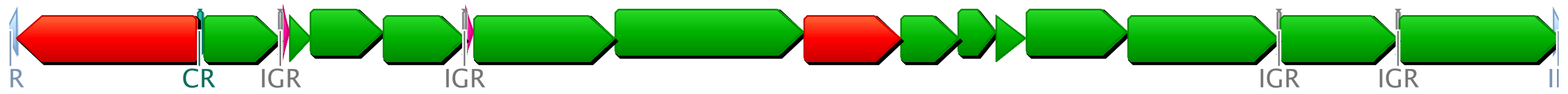

(1) Transcription of polycistronic pre-mRNA

(2) mt-mRNA maturation

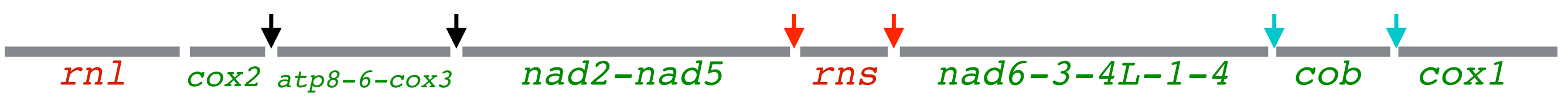


Figure 3 (on next page)

Phylogenetic analysis of the allNT alignment under the Bayesian framework using MrBayes with the GTR $+\Gamma$ model of sequence evolution.

Support values correspond to posterior probabilities. 


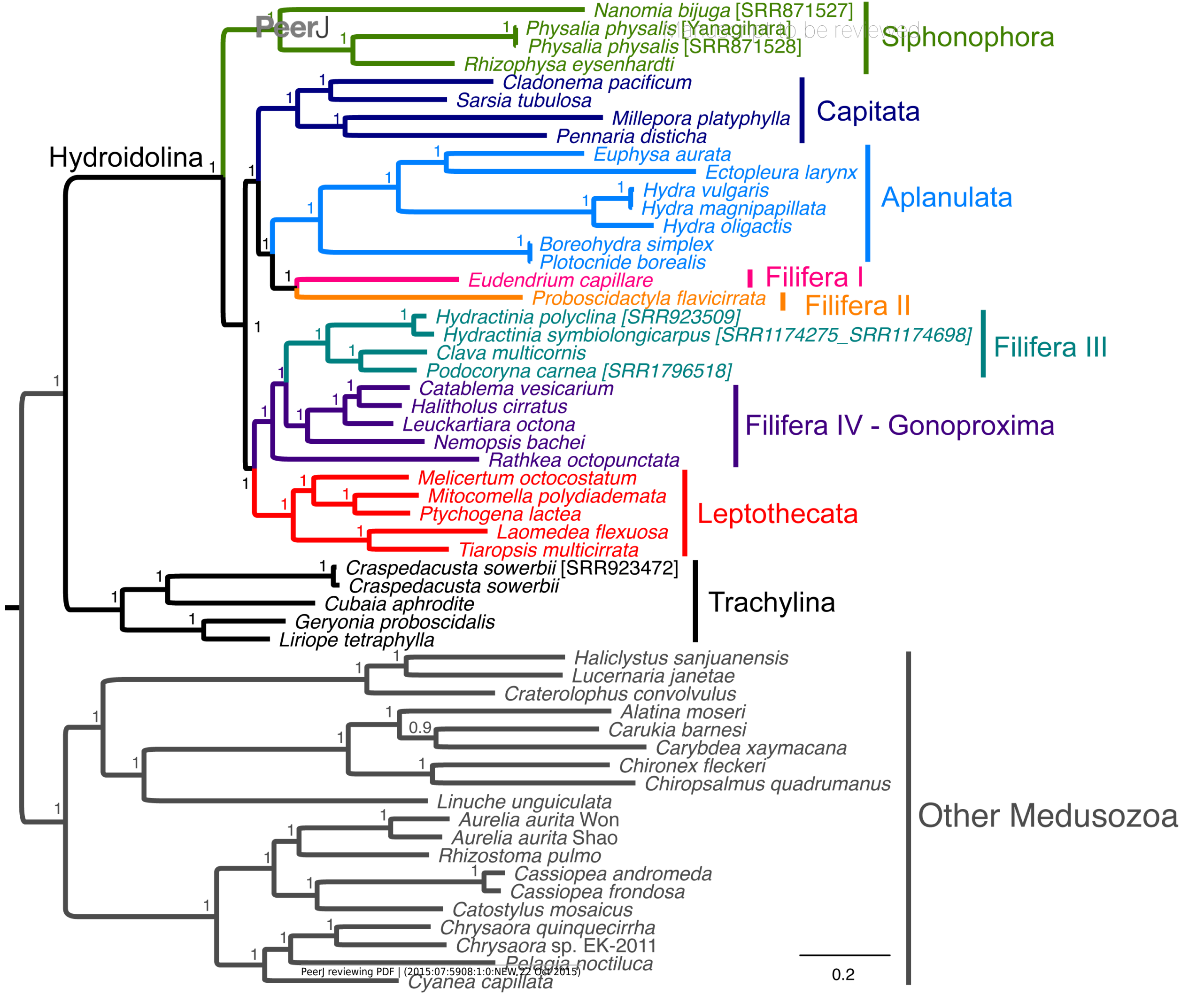


Figure 4 (on next page)

2-dimensional plots of the first two principal components from the principal component analysis of the composition of the AA (A), rRNA (B), NT (C) and allNT (D) alignments. 

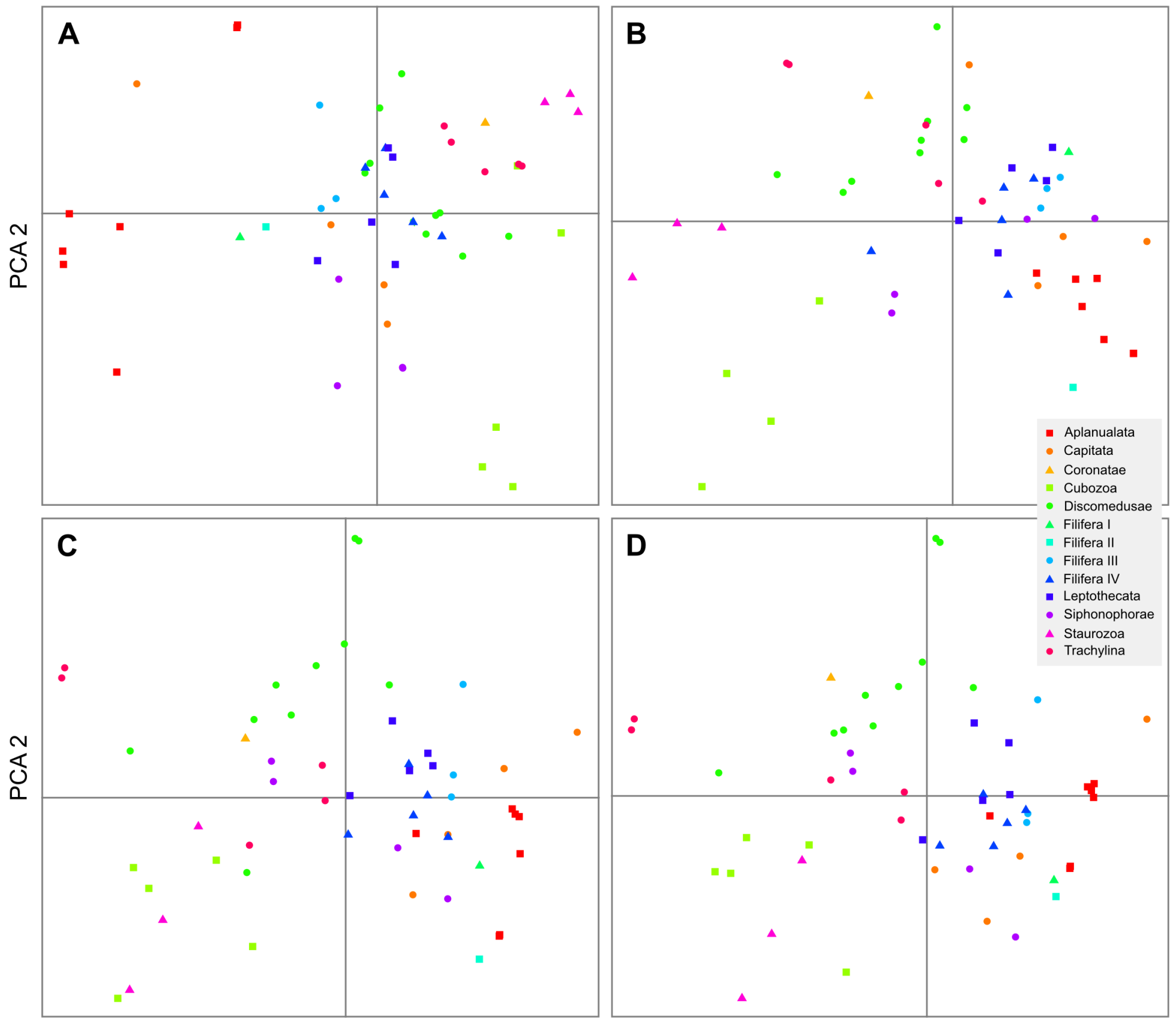

PCA 1

PCA 1 


\section{Table $\mathbf{1}$ (on next page)}

List of samples used in this study.

Colore-filled taxa were obtained for this study. DNA-seq data is shaded in green; RNA-seq data is shaded in magenta long-range PCR amplified samples are shaded in cyan; * not included in phylogenetic analyses; SRR codes are GenBank Archive numbers of the runs used in this study. 


\begin{tabular}{|c|c|c|c|c|}
\hline Clade & Species & Voucher \# & GenBank \# & Note \\
\hline \multirow[t]{8}{*}{ Aplanulata } & Boreohydra simplex & Borehydra20100904.3 & KT809334 & \\
\hline & Ectopleura larynx & & JN700938 & \\
\hline & Ectopleura larynx* & & processing & SRR923510 \\
\hline & Euphysa aurata & GR10-145.2 & KT809330 & \\
\hline & Hydra oligactis & & NC_010214 & \\
\hline & Hydra magnipapillata & & NC_011220,NC_011221 & \\
\hline & Hydra vulgaris & & HM369413,HM3̄69414 & \\
\hline & Plotocnide borealis & RU087.1 & KT809334 & \\
\hline \multirow[t]{4}{*}{ Capitata } & Cladonema pacificum & & KT809323 & Unpublished raw reads \\
\hline & Millepora platyphylla & & JN700943 & old Millepora EK-2011 \\
\hline & Pennaria disticha & & JN700950 & \\
\hline & Sarsia tubulosa & RU053 & KT809333 & \\
\hline \multirow{11}{*}{$\begin{array}{l}\mathrm{I} \\
\mathrm{I} \\
\mathrm{I} \\
\mathrm{I} \\
\mathrm{I} \\
\mathrm{I} \\
\mathrm{I} \\
\mathrm{I}\end{array}$} & V Catablema vesicarium & RU006 & KT809324 & \\
\hline & II Clava multicornis & & NC_016465 & \\
\hline & I Eudendrium capillare & PS101 & KT809336 & \\
\hline & V Halitholus cirratus & GR10-115 & KT809337 & \\
\hline & II Hydractinia polyclina & & processing & SRR923509 \\
\hline & II Hydractinia symbiolongicarpus & & processing & SRR1174275 \& SRR1174698 \\
\hline & V Leuckartiara octona & PS487 & KT809325 & \\
\hline & V Nemopsis bachei & & JN700947 & \\
\hline & II Podocoryna carnea & & processing & SRR1796518 \\
\hline & II Proboscidactyla flavicirrata & PS139 & КТ809319,КТ809329 & \\
\hline & V Rathkea octopunctata & RU008 & HТ 809320 & \\
\hline \multirow[t]{5}{*}{ Leptothecata } & Laomedea flexuosa & & NC_016463 & \\
\hline & Melicertum octocostatum & RU082 & KT809321 & \\
\hline & Mitrocomella polydiademata & RU060 & KT809332 & \\
\hline & Ptychogena lactea & GR10-152.1 & KT809322 & \\
\hline & Tiaropsis multicirrata & GR10-053.1 & KT809326 & \\
\hline \multirow[t]{4}{*}{ Siphonophorae } & Nanomia bijuga & & processing & SRR871527 \\
\hline & Physalia physalis & & processing & SRR871528 \\
\hline & Physalia physalis & Angel & KT809328 & Unpublished raw reads \\
\hline & Rhizophysa eysenhardti & DLSI230 & KT809335 & \\
\hline \multirow[t]{5}{*}{ Trachylina } & Craspedacusta sowerbyi & & NC 018537 & \\
\hline & Craspedacusta sowerbyi & & processing & SRR923472 \\
\hline & Cubaia aphrodite & & NC_016467 & \\
\hline & Geryonia proboscidalis & BCS32a & KT809331 & \\
\hline & Liriope tetraphylla & & KT809327 & Unpublished raw reads \\
\hline \multirow[t]{10}{*}{ Discomedusae } & Aurelia aurita & & NC_008446 & Shao \\
\hline & Aurelia aurita & & HQ6̄94729 & Won \\
\hline & Cassiopea andromeda & & JN700934 & \\
\hline & Cassiopea frondosa & & NC_016466 & \\
\hline & Catostylus mosaicus & & JN700940 & \\
\hline & Chrysaora quinquecirrha & & HQ694730 & \\
\hline & Chrysaora sp. EK-2011 & & JN700941 & \\
\hline & Cyanea capillata & & JN700937 & \\
\hline & Rhizostoma pulmo & & JN700987,JN700988 & \\
\hline & Pelagia noctiluca & & JN700949 & \\
\hline Coronatae & Linuche unguiculata & & JN700939 & \\
\hline \multirow[t]{3}{*}{ Staurozoa } & Craterolophus convolvulus & & JN700975,JN700976 & \\
\hline & Haliclystus sanjuanensis & & JN700944 & \\
\hline & Lucernaria janetae & & JN700946 & \\
\hline \multirow[t]{5}{*}{ Cubozoa } & Alatina moseri & & JN642330-JN642344 & \\
\hline & Carukia barnesi & & JN700959-JN700962 & \\
\hline & Carybdea xaymacana & & JN700977-JN700983 & \\
\hline & Chironex fleckeri & & JN700963-JN700968 & \\
\hline & Chiropsalmus quadrumanus & & JN700969-JN700974 & \\
\hline
\end{tabular}




\section{Table 2 (on next page)}

Size, GC content and start and end codons for the genes of the newly obtained mtDNA.

B. s.: Boreohydra simplex; C. v.: Catablema vesicarium; C. p.: Cladonema pacificum; C. s. RNA:Craspedacusta sowerbyi; E.I. RNA: Ectopleura larynx; E. c.: Eudendrium capillare; E. a.: Euphysa aurata; G. p.: Geryonia proboscidalis; H. c.: Halitholus cirratus; H. p.: Hydractinia polyclina; H. s.: Hydractinia symbiolongicarpus; L. o.: Leuckartiara octona; L. t.: Liriope tetraphylla; M. o.: Melicertum octocostatum; M. p.: Mitrocomella polydiademata; N. b.: Nanomia bijuga; P. p. Y: Physalia physalis Y; P. p. SR: Physalia physalis SR; P. b.: Plotocnide borealis; P. c. ;Podocoryna carnea; P. f.: Proboscidactyla flavicirrata; P. I.: Ptychogena lactea; R. o.: Rathkea octopunctata; R. e.: Rhizophysa eysenhardti; S. t.: Sarsia tubulosa; T. m.: Tiaropsis multicirrata. 


\begin{tabular}{|c|c|c|c|c|c|c|c|c|c|c|c|c|c|c|c|c|c|c|c|c|c|c|c|c|c|c|c|}
\hline Gene & & B.s. & & & $\begin{array}{c}\text { C.s. } \\
\text { RNA }\end{array}$ & $\begin{array}{c}\text { E.l. } \\
\text { RNA }\end{array}$ & & & & & & & & & $M o$ & An & $N$ & & $\begin{array}{l}\text { P.p. } \\
\text { SR }\end{array}$ & P. $b$. & & P.f. & P.l. & $R o$ & $R e$ & $S t$ & T.m. \\
\hline & $\mathrm{fe}(\mathrm{nt})$ & 705 & 705 & 705 & 705 & 705 & 705 & 705 & 705 & 705 & 705 & 705 & 705 & 705 & 705 & 705 & 693 & 705 & 705 & 705 & 705 & ? & 705 & 705 & 705 & 705 & 705 \\
\hline \multirow[t]{3}{*}{ atp6 } & GC & 22.4 & & 24.8 & 45.1 & 28.3 & 2.6 & 22 & 30.1 & 6.2 & 25.2 & & & 29.8 & 27.1 & 29.4 & 25.7 & 32.3 & 32.9 & 22.3 & 25.7 & $?$ & 25.5 & 28.8 & 28.5 & 25.8 & 27.4 \\
\hline & Start/End & /A & $\mathrm{A} / \mathrm{A}$ & $\mathrm{A} / \mathrm{A}$ & $\mathrm{A} / \mathrm{A}$ & $\mathrm{A} / \mathrm{A}$ & $\mathrm{A} / \mathrm{A}$ & $\mathrm{A} / \mathrm{A}$ & $\mathrm{A} / \mathrm{A}$ & $\mathrm{A} / \mathrm{A}$ & $\mathrm{A} / \mathrm{A}$ & $\mathrm{A} / \mathrm{A}$ & & $\mathrm{A} / \mathrm{A}$ & $\mathrm{A} / \mathrm{A}$ & $\mathrm{A} / \mathrm{A}$ & $\mathrm{A} / \mathrm{A}$ & $\mathrm{A} / \mathrm{A}$ & $\mathrm{A} / \mathrm{A}$ & $\mathrm{A} / \mathrm{A}$ & $\mathrm{A} / \mathrm{A}$ & $?$ & A/A & $\mathrm{A} / \mathrm{A}$ & $\mathrm{A} / \mathrm{A}$ & $\mathrm{A} / \mathrm{A}$ & $\mathrm{A} / \mathrm{A}$ \\
\hline & size (nt) & 198 & 204 & 207 & 207 & 207 & 204 & 213 & 207 & 204 & 204 & 204 & 204 & 207 & 204 & 204 & $?$ & $>126$ & 204 & 198 & 204 & $?$ & 204 & 204 & 201 & 204 & 198 \\
\hline \multirow[t]{3}{*}{ atp 8} & $\mathrm{GC}$ & 3.1 & 22.1 & 16.4 & 39.1 & 21.4 & 5.7 & 14.1 & 29.5 & 8.1 & 17.5 & 17.6 & & 30 & 22.1 & 20.6 & : & 20.6 & 24 & & 21.6 & $?$ & 2.1 & & 18.9 & 20.6 & 21.7 \\
\hline & Start/End & T/A & $\mathrm{A} / \mathrm{A}$ & $\mathrm{A} / \mathrm{A}$ & $\mathrm{A} / \mathrm{A}$ & $\mathrm{A} / \mathrm{A}$ & $\mathrm{A} / \mathrm{A}$ & $\mathrm{A} / \mathrm{A}$ & $\mathrm{A} / \mathrm{A}$ & $\mathrm{A} / \mathrm{A}$ & $\mathrm{A} / \mathrm{A}$ & $\mathrm{A} / \mathrm{A}$ & & $\mathrm{A} / \mathrm{A}$ & $\mathrm{A} / \mathrm{A}$ & $\mathrm{A} / \mathrm{A}$ & $?$ & ?/A & $\mathrm{A} / \mathrm{A}$ & $\mathrm{T} / \mathrm{A}$ & $\mathrm{A} / \mathrm{A}$ & $?$ & $\mathrm{~A} / \mathrm{A}$ & $\mathrm{A} / \mathrm{A}$ & $\mathrm{A} / \mathrm{A}$ & $\mathrm{A} / \mathrm{A}$ & $\mathrm{G} / \mathrm{A}$ \\
\hline & size $(\mathrm{nt})$ & 1149 & 114 & 1140 & 1185 & $>1024$ & 1143 & 1140 & $>787$ & 1140 & 1143 & 1143 & 1140 & 01203 & 1143 & 1146 & 1164 & $>1016$ & $>1133$ & 31149 & 91143 & $3>848$ & 1146 & 1146 & 1143 & 1143 & 1146 \\
\hline \multirow[t]{3}{*}{$c o b$} & $\mathrm{GC}$ & 25.5 & 27.5 & 27.8 & 46 & 29.7 & 25.9 & 26.3 & 36.5 & 27.3 & 27.5 & 27. & & 2.3 & 29.3 & 31.8 & 29.2 & 36.5 & 35 & 25.4 & 9.1 & 25.9 & 27.4 & 33 & 28.4 & 28.6 & 30.6 \\
\hline & Start/End & $\mathrm{A} / \mathrm{A}$ & $\mathrm{A} / \mathrm{A}$ & $\mathrm{A} / \mathrm{A}$ & $\mathrm{A} / \mathrm{G}$ & $\mathrm{A} / ?$ & $\mathrm{~A} / \mathrm{A}$ & $\mathrm{A} / \mathrm{A}$ & $\mathrm{A} /$ ? & $\mathrm{A} / \mathrm{A}$ & $\mathrm{A} / \mathrm{A}$ & $\mathrm{A} / \mathrm{A}$ & & $\mathrm{A} / \mathrm{G}$ & $\mathrm{A} / \mathrm{G}$ & $\mathrm{A} / \mathrm{A}$ & $\mathrm{A} / \mathrm{A}$ & $? / ?$ & $? / \mathrm{A}$ & $\mathrm{A} / \mathrm{A}$ & $\mathrm{A} / \mathrm{A}$ & $\mathrm{A} /$ ? & $\mathrm{A} / \mathrm{A}$ & $\mathrm{A} / \mathrm{A}$ & $\mathrm{A} / \mathrm{A}$ & $\mathrm{A} / \mathrm{A}$ & $\mathrm{G} / \mathrm{A}$ \\
\hline & size (nt) & $>712$ & $>70$ & 1566 & 51566 & $>1569$ & $>884$ & $>713$ & $>1322$ & $2>910$ & 1566 & & $5>919$ & 91566 & $>713$ & $>699$ & 1572 & $>1548$ & 1566 & $>715$ & 51566 & $5>822$ & $>713$ & $>710$ & $>711$ & $>713$ & $>713$ \\
\hline \multirow[t]{3}{*}{$\operatorname{cox} 1$} & GC & 33 & 35.3 & 33.1 & 46.2 & 34.7 & 32.5 & 32 & 38 & 35.1 & 32.2 & & 4.1 & & 35.2 & 38.2 & 32.6 & 38.4 & 38.1 & 33 & 34.4 & 32.2 & 34.5 & 37.5 & 33.8 & 33.5 & 34.2 \\
\hline & Start/End & $\mathrm{A} /$ ? & $\mathrm{A} / ?$ & $\mathrm{~A} / \mathrm{G}$ & $\mathrm{A} / \mathrm{G}$ & $? / ?$ & $\mathrm{~A} / ?$ & $\mathrm{G} /$ ? & $\mathrm{A} /$ ? & $\mathrm{A} /$ ? & $\mathrm{A} / \mathrm{G}$ & & & $\mathrm{A} / \mathrm{G}$ & $\mathrm{A} / ?$ & $\mathrm{~A} / ?$ & $\mathrm{~A} / \mathrm{A}$ & ?/A & $\mathrm{A} / \mathrm{A}$ & $\mathrm{A} /$ ? & $\mathrm{A} / \mathrm{G}$ & $? / ?$ & $\mathrm{~A} / ?$ & $\mathrm{~A} /$ ? & $\mathrm{A} /$ ? & $\mathrm{A} /$ ? & $\mathrm{A} /$ ? \\
\hline & size (nt) & 726 & 738 & 738 & 738 & $>939$ & 738 & 768 & 741 & 738 & 738 & 738 & 738 & 741 & 738 & 738 & $>720$ & $>720$ & 735 & 726 & 738 & $?$ & 738 & 738 & 735 & 738 & 735 \\
\hline \multirow[t]{3}{*}{$\cos 2$} & GC & 25.8 & 29.5 & 28.6 & 44.3 & 27.6 & 28.6 & 22.3 & 37.2 & 9.7 & 28.1 & 28.2 & 29 & 32.1 & 30.8 & 34.1 & 31.4 & 39.2 & 38.5 & 25.8 & 9.7 & & & 32 & 2.4 & 9.3 & 29.3 \\
\hline & Start & $\mathrm{A} / \mathrm{A}$ & $\mathrm{A} / \mathrm{A}$ & $\mathrm{A} / \mathrm{A}$ & $\mathrm{A} / \mathrm{A}$ & ?/A & $\mathrm{A} / \mathrm{A}$ & $\mathrm{A} / \mathrm{A}$ & $\mathrm{A} / \mathrm{G}$ & $\mathrm{A} / \mathrm{A}$ & $\mathrm{A} / \mathrm{A}$ & $\mathrm{A} / \mathrm{A}$ & $\mathrm{A} / \mathrm{A}$ & $\mathrm{A} / \mathrm{G}$ & $\mathrm{A} / \mathrm{A}$ & $\mathrm{A} / \mathrm{A}$ & $? / \mathrm{G}$ & ?/? & $\mathrm{A} / \mathrm{A}$ & $\mathrm{A} / \mathrm{A}$ & $\mathrm{A} / \mathrm{A}$ & $?$ & $\mathrm{~A} / \mathrm{A}$ & $\mathrm{A} / \mathrm{A}$ & $\mathrm{A} / \mathrm{A}$ & $\mathrm{A} / \mathrm{A}$ & $\mathrm{A} / \mathrm{A}$ \\
\hline & size & 786 & 786 & 786 & 786 & $>778$ & 786 & 786 & 786 & 786 & 786 & 786 & 786 & 786 & 786 & 786 & $>798$ & 786 & 786 & 786 & 786 & $?$ & 786 & 786 & 789 & 786 & 786 \\
\hline \multirow[t]{3}{*}{$\cos 3$} & GC & 26.5 & 29.8 & 30.4 & 45.2 & 30.6 & 28.4 & 24 & 39.6 & 31.7 & 28.5 & 29.1 & 29.5 & 34.6 & 31.6 & 36.5 & 30.3 & 37.8 & 37.5 & 26.3 & 330 & $?$ & 1.7 & 32.8 & 32.6 & 32.1 & 33.3 \\
\hline & Start & $\mathrm{A} / \mathrm{A}$ & $\mathrm{A} / \mathrm{A}$ & $\mathrm{A} / \mathrm{A}$ & $\mathrm{A} / \mathrm{A}$ & $\mathrm{A} /$ ? & $\mathrm{A} / \mathrm{A}$ & $\mathrm{A} / \mathrm{A}$ & $\mathrm{A} / \mathrm{A}$ & $\mathrm{A} / \mathrm{A}$ & $\mathrm{A} / \mathrm{A}$ & $\mathrm{A} / \mathrm{A}$ & & $\mathrm{A} / \mathrm{A}$ & $\mathrm{A} / \mathrm{A}$ & $\mathrm{A} / \mathrm{A}$ & $\mathrm{A} / ?$ & $\mathrm{~A} / \mathrm{A}$ & $\mathrm{A} / \mathrm{A}$ & $\mathrm{A} / \mathrm{A}$ & $\mathrm{A} / \mathrm{A}$ & $?$ & $\mathrm{~A} / \mathrm{A}$ & $\mathrm{A} / \mathrm{A}$ & $\mathrm{A} / \mathrm{A}$ & $\mathrm{A} / \mathrm{A}$ & $\mathrm{A} / \mathrm{G}$ \\
\hline & size & 978 & 990 & 987 & 999 & 981 & 990 & 990 & 999 & 990 & $>972$ & 990 & 990 & 999 & 987 & 987 & 990 & 990 & 990 & 978 & 990 & 987 & 990 & 987 & 987 & 990 & 990 \\
\hline \multirow[t]{3}{*}{ nadl } & GC & 24.7 & 28 & 26.6 & 46.9 & 28.7 & 27.2 & 23.6 & 37 & 30.5 & 25.2 & 26.7 & 27 & 33.4 & 28 & 31.9 & 26.2 & 36.1 & 5.8 & & 727.8 & 24 & 27 & & 0.4 & 27.5 & 28.5 \\
\hline & Star & $\mathrm{A} / \mathrm{A}$ & $\mathrm{A} / \mathrm{A}$ & $\mathrm{A} / \mathrm{A}$ & $\mathrm{A} / \mathrm{A}$ & $\mathrm{A} / \mathrm{G}$ & $\mathrm{A} / \mathrm{A}$ & $\mathrm{A} / \mathrm{A}$ & $\mathrm{A} / \mathrm{A}$ & $\mathrm{A} / \mathrm{A}$ & $\mathrm{A} / ?$ & $\mathrm{~A} / \mathrm{G}$ & $\mathrm{A} / \mathrm{A}$ & $\mathrm{A} / \mathrm{A}$ & $\mathrm{A} / \mathrm{A}$ & $\mathrm{A} / \mathrm{A}$ & $\mathrm{A} / \mathrm{A}$ & $\mathrm{G} / \mathrm{A}$ & $\mathrm{G} / \mathrm{A}$ & $\mathrm{A} /$ & $\mathrm{A} / \mathrm{A}$ & $\mathrm{A} / \mathrm{A}$ & & & A & G & $\mathrm{l} / \mathrm{A}$ \\
\hline & size & 1311 & 136 & 21314 & 41350 & $>893$ & 1353 & 1311 & 1353 & 1362 & $>1038$ & 81362 & 21362 & 21353 & 1350 & 356 & $?$ & $>1176$ & 1338 & & 11356 & $5 ?$ & & 344 & 353 & 356 & 347 \\
\hline \multirow[t]{3}{*}{$\operatorname{nad} 2$} & GC & 17.7 & 22.5 & 19.9 & 44 & 25.1 & 17.4 & 15.7 & 32.8 & 2.2 & 21 & 19.8 & 20.7 & 28.5 & 24.4 & 27 & ? & 32.2 & 31.3 & 178 & 1.2 & $?$ & & 26.6 & 23.4 & 23.5 & 3.2 \\
\hline & Start & $\mathrm{A} / \mathrm{A}$ & $\mathrm{G} / \mathrm{A}$ & $\mathrm{A} / \mathrm{A}$ & $\mathrm{A} / \mathrm{A}$ & $? / ?$ & $\mathrm{~A} / \mathrm{A}$ & $\mathrm{A} / \mathrm{A}$ & $\mathrm{A} / \mathrm{A}$ & $\mathrm{G} / \mathrm{A}$ & $? / ?$ & $\mathrm{~A} / \mathrm{A}$ & $\mathrm{A} / \mathrm{A}$ & $\mathrm{A} / \mathrm{A}$ & $\mathrm{A} / \mathrm{A}$ & $\mathrm{A} / \mathrm{A}$ & $?$ & ?/A & $\mathrm{A} / \mathrm{A}$ & $\mathrm{A} / \mathrm{A}$ & $\mathrm{A} / \mathrm{A}$ & $?$ & $\mathrm{~A} / \mathrm{A}$ & $\mathrm{A} / \mathrm{A}$ & $\mathrm{A} / \mathrm{A}$ & $\mathrm{A} / \mathrm{A}$ & $\mathrm{A} / \mathrm{A}$ \\
\hline & size & 360 & 357 & 357 & 357 & 357 & 357 & 357 & 357 & 357 & 357 & 357 & 357 & 357 & 357 & 357 & 357 & 357 & 357 & 360 & 357 & 357 & 357 & 357 & 357 & 357 & 357 \\
\hline nad3 & GC & 23.3 & 24.6 & 22.1 & 42.3 & 24.3 & 22.1 & 21.8 & 34.2 & 5.5 & 22.4 & & 22.1 & 30.8 & 26.6 & 29.1 & 23.5 & 30 & 30.3 & 23.6 & & 23 & & & 6.9 & 28 & 25.8 \\
\hline & Start & $\mathrm{A} / \mathrm{A}$ & $\mathrm{A} / \mathrm{A}$ & $\mathrm{A} / \mathrm{A}$ & $\mathrm{A} / \mathrm{A}$ & $\mathrm{A} / \mathrm{A}$ & $\mathrm{A} / \mathrm{A}$ & $\mathrm{A} / \mathrm{A}$ & $\mathrm{A} / \mathrm{A}$ & $\mathrm{A} / \mathrm{A}$ & $\mathrm{A} / \mathrm{A}$ & & & & $\mathrm{A} / \mathrm{A}$ & $\mathrm{A} / \mathrm{A}$ & $\mathrm{A} / \mathrm{A}$ & G/A & $\mathrm{G} / \mathrm{A}$ & & & $\mathrm{A} / \mathrm{A}$ & A & $\mathrm{V} / \mathrm{A}$ & $\mathrm{A} / \mathrm{A}$ & $\mathrm{A} / \mathrm{A}$ & $\mathrm{A} / \mathrm{A}$ \\
\hline & & 1455 & 1458 & 1458 & 31461 & 458 & 1449 & 1458 & 1461 & 1458 & $>1251$ & & 31 & & 1455 & 1455 & $>974$ & $>1111$ & $>1315$ & & 458 & 31446 & 55 & 458 & 461 & 1458 & 1455 \\
\hline$d 4$ & $\mathrm{GC}$ & 22.6 & 25 & 24.3 & 44.6 & 26.3 & 21.5 & 20.2 & 35.8 & 4.6 & 24.7 & & 2 & 32.2 & 26.7 & 29.9 & 27.3 & 33.1 & 33.1 & & 25.7 & 2 & & & & .1 & 7.2 \\
\hline & Start & $\mathrm{A} / \mathrm{A}$ & $\mathrm{A} / \mathrm{A}$ & $\mathrm{A} / \mathrm{A}$ & $\mathrm{A} / \mathrm{A}$ & $\mathrm{A} / \mathrm{A}$ & $\mathrm{A} / \mathrm{A}$ & $\mathrm{A} / \mathrm{A}$ & $\mathrm{d} / \mathrm{G}$ & /A & ?/A & $\mathrm{A} / \mathrm{A}$ & A/A & $\mathrm{A} / \mathrm{G}$ & $\mathrm{A} / \mathrm{A}$ & $\mathrm{A} / \mathrm{G}$ & $? / ?$ & $\mathrm{~A} /$ ? & $\mathrm{A} /$ ? & A/ & $\mathrm{A} / \mathrm{A}$ & $\mathrm{A} / \mathrm{A}$ & & & /G & /A & $\mathrm{A} / \mathrm{A}$ \\
\hline & & 297 & 300 & 294 & 300 & 300 & 300 & 300 & 00 & 300 & 300 & 300 & 300 & 300 & 300 & 300 & $>279$ & 297 & 297 & 297 & 300 & 297 & 300 & 97 & 00 & 297 & 300 \\
\hline$d 4 L$ & $L \mathrm{GC}$ & 20.5 & 20.7 & 21.1 & 40 & 21.7 & 20.7 & 19.7 & 29.3 & 21.3 & 16.9 & 19 & 20.3 & 26.3 & 24 & 1.3 & 26.9 & 26.9 & 7.3 & 2 & & 19.9 & 22 & .3 & 22.7 & 23.9 & 26.3 \\
\hline & Start/ & $\mathrm{A} / \mathrm{A}$ & $\mathrm{A} / \mathrm{A}$ & G/A & $\mathrm{A} / \mathrm{A}$ & $\mathrm{A} / \mathrm{A}$ & $\mathrm{A} / \mathrm{A}$ & $\mathrm{A} / \mathrm{A}$ & $\mathrm{A} / \mathrm{A}$ & $\mathrm{A} / \mathrm{A}$ & $\mathrm{A} / \mathrm{A}$ & $\mathrm{A} / \mathrm{A}$ & $\mathrm{A} / \mathrm{A}$ & $\mathrm{A} / \mathrm{A}$ & $\mathrm{A} / \mathrm{A}$ & $\mathrm{A} / \mathrm{A}$ & $\mathrm{G} / \mathrm{G}$ & $\mathrm{A} / \mathrm{G}$ & $\mathrm{A} / \mathrm{G}$ & $\mathrm{A} / \mathrm{A}$ & $\mathrm{A} / \mathrm{A}$ & $\mathrm{A} / \mathrm{A}$ & $\mathrm{A} / \mathrm{A}$ & $\mathrm{A} / \mathrm{A}$ & $\mathrm{A} / \mathrm{A}$ & $\mathrm{A} / \mathrm{A}$ & $\mathrm{A} / \mathrm{A}$ \\
\hline & size & 1827 & 183 & 1830 & 1833 & $>1730$ & 1830 & 1853 & 1833 & 1833 & $>1672$ & 21833 & 1833 & 31833 & 1833 & 1833 & $>1813$ & $3>1719$ & 1830 & 1830 & 01833 & $3>1137$ & 71833 & 1833 & 1830 & 1833 & 1833 \\
\hline ad5 & GC & 21.1 & 25.3 & 25.1 & 46.3 & & 22.8 & & 36.1 & & 24.7 & & & 32.3 & 26 & & & 34.1 & 34.1 & & 25.6 & & & & & 6.7 & 27.1 \\
\hline & Start & $\mathrm{T} / \mathrm{A}$ & $\mathrm{A} / \mathrm{G}$ & $\mathrm{A} / \mathrm{G}$ & $\mathrm{A} / \mathrm{A}$ & !l! & $\mathrm{A} / \mathrm{G}$ & $\mathrm{A} / \mathrm{A}$ & $\mathrm{A} / \mathrm{A}$ & & $? / ?$ & & $1 / 4$ & $\mathrm{~A} / \mathrm{A}$ & $\mathrm{A} / \mathrm{G}$ & & $? / ?$ & & $\mathrm{~A} / \mathrm{A}$ & $1 /$ & $\mathrm{A} / \mathrm{G}$ & & G & & A & $/ \mathrm{G}$ & $\mathrm{A} / \mathrm{G}$ \\
\hline & & 567 & 561 & 549 & 564 & 58 & 52 & 555 & 64 & 561 & 564 & 56 & 561 & 564 & 56 & & 552 & 555 & 561 & & 564 & 50 & & & & 52 & 561 \\
\hline nad6 & GC & 19.2 & 23 & 21.3 & 44 & 22.4 & 18.8 & 17.5 & 30.3 & 24.1 & 20.2 & 20.6 & 20.9 & 28 & 25.4 & 25.4 & 20.1 & 32.4 & 33 & 1 & 3.8 & 19.1 & 1.6 & 28.5 & 26.6 & 23.7 & 25 \\
\hline & Start/End & $\mathrm{A} / \mathrm{A}$ & $\mathrm{G} / \mathrm{G}$ & $\mathrm{A} / \mathrm{G}$ & $\mathrm{A} / \mathrm{G}$ & $\mathrm{A} / \mathrm{A}$ & $\mathrm{A} / \mathrm{G}$ & $\mathrm{A} / \mathrm{A}$ & $\mathrm{A} / \mathrm{G}$ & $\mathrm{A} / \mathrm{G}$ & $\mathrm{A} / \mathrm{G}$ & $\mathrm{A} / \mathrm{G}$ & $\mathrm{A} / \mathrm{G}$ & $\mathrm{A} / \mathrm{G}$ & $\mathrm{A} / \mathrm{G}$ & $\mathrm{A} / \mathrm{G}$ & $? / \mathrm{G}$ & $? / \mathrm{G}$ & $\mathrm{A} / \mathrm{G}$ & $\mathrm{A} / \mathrm{A}$ & $\mathrm{A} / \mathrm{G}$ & $\mathrm{A} / \mathrm{A}$ & $\mathrm{A} / \mathrm{G}$ & $\mathrm{A} / \mathrm{G}$ & $\mathrm{A} / \mathrm{G}$ & $\mathrm{A} / \mathrm{G}$ & $\mathrm{A} / \mathrm{A}$ \\
\hline & size (nt) & $>743$ & $>159$ & 21720 & $>1784$ & $4>1784$ & $>1303$ & $3>775$ & $>600$ & $>1590$ & 1733 & 1737 & $7>892$ & 21768 & $>1591$ & $1>1581$ & $1>1759$ & 91761 & 1756 & & & $>505$ & $>1588$ & $8>1586$ & $6>1613$ & $3>1581$ & $1>158$ \\
\hline & $\mathrm{GC}$ & 24.9 & 23.9 & 23.3 & 36.5 & 26.4 & 20.3 & 23.7 & 39.1 & 24.5 & 23.9 & 24.8 & 9.4 & 27.1 & 24.5 & 27.2 & 22 & 32.3 & 32.5 & 24.9 & 24.1 & 26.9 & 24.4 & 31.7 & 23.5 & 24.4 & 26.3 \\
\hline & & 930 & 930 & 912 & 995 & $>865$ & & & & & $>910$ & 931 & 928 & 968 & 92 & & $>845$ & $>873$ & 922 & 930 & 931 & 906 & & & 926 & 915 & 920 \\
\hline$n s$ & GC & 21 & 27.8 & 23.6 & 37.6 & 24.9 & 25.3 & 22.5 & 31.3 & 28.1 & 25.6 & 25.6 & 27.6 & 29.1 & 25.7 & 26.6 & 23.2 & 32 & 31.5 & 21 & 24.9 & 25.1 & 26.5 & 32.9 & 26.6 & 25 & 29.7 \\
\hline & size & 74 & & 71 & 71 & $?$ & 71 & $?$ & 71 & 7 & $?$ & & 71 & 71 & 7 & & $?$ & & 69 & 74 & ( & & & & & 71 & 69 \\
\hline & GC & 24.3 & 23.9 & 33.8 & 36.6 & $?$ & 26.8 & $?$ & 28.2 & 23.9 & $?$ & 29.6 & 23.9 & 26.8 & 26.8 & 30.4 & $?$ & $?$ & 37.7 & 24.3 & 328.4 & $?$ & 27.5 & 34.8 & 27.5 & 31 & 30.4 \\
\hline & size (nt) & 70 & 70 & 70 & 71 & $?$ & 70 & 70 & 71 & 70 & $?$ & 70 & 70 & 71 & 70 & 70 & $?$ & $?$ & $?$ & 70 & 70 & $?$ & 70 & 70 & 70 & 70 & 70 \\
\hline & $\mathrm{GC}$ & 25.7 & 35.7 & 34.3 & 47.9 & $?$ & 32.9 & 30 & 40.8 & 35.7 & $?$ & 34.3 & 41.4 & 39.4 & 35.7 & 32.9 & $?$ & $?$ & $?$ & 25.7 & 734.4 & $?$ & 28.6 & 44.3 & 28.6 & 34.3 & 35.7 \\
\hline & size & NA & NA & NA & 354 & & & NA & $?$ & & NA & NA & NA & 297 & NA & NA & & & NA & NA & NA & $\mathrm{NA}$ & & $\mathrm{A}$ & NA & IA & NA \\
\hline & $4 \mathrm{GC}$ & NA & NA & NA & 37.9 & & & $\mathrm{~N}$ & ? & & & NA & NA & 22.2 & $\mathrm{~N}$ & & & & & NA & NA & $\mathrm{N}$ & & & A & A & NA \\
\hline & Start & NA & NA & NA & $\mathrm{A} / \mathrm{A}$ & & $\mathrm{JA}$ & NA & $?$ & & NA & NA & NA & $\mathrm{A} / \mathrm{A}$ & NA & $\mathrm{N}$ & $\mathrm{N}$ & NA & NA & NA & NA & NA & A & A & NA & NA & NA \\
\hline & & NA & $\mathrm{NA}$ & $\mathrm{NA}$ & 1668 & & & $\mathrm{~N}$ & $?$ & & & $\mathrm{~N}$ & $\mathrm{~N}$ & 1644 & $\mathrm{~N}$ & & & & & NA & NA & $\mathrm{N}$ & & & & A & A \\
\hline$o l B$ & GC & NA & NA & NA & 41.7 & NA & NA & NA & $?$ & & NA & $\mathrm{N}$ & $\mathrm{N}$ & 30.4 & $\mathrm{~N}$ & $\mathrm{~N}$ & & NA & $\mathrm{N}$ & NA & NA & NA & & & NA & NA & NA \\
\hline & Start/End & NA & NA & NA & $\mathrm{A} / \mathrm{A}$ & NA & NA & NA & $?$ & NA & NA & NA & NA & $\mathrm{A} / \mathrm{A}$ & NA & NA & NA & NA & NA & NA & NA & NA & NA & NA & NA & NA & NA \\
\hline
\end{tabular}




\section{Table 3(on next page)}

Posterior probabilities and bootstrap values for different clades within Hydrozoa. 


\begin{tabular}{lcccc|ccccc}
\hline & \multicolumn{4}{c|}{ MB } & \multicolumn{5}{c}{ ML } \\
& aa(GTR) & NT(GTR) & rRNA(GTR) & allNT(GTR) & AA(GTR) & AA(LG) & NT(GTR) & rRNA(GTR) allNT(GTR) \\
\hline Aplanulata & 1 & 1 & 1 & 1 & 100 & 100 & 100 & 88 & 100 \\
Capitata & 0.95 & 1 & 1 & 1 & NA & NA & 63 & 94 & 99 \\
Filifera & NA & NA & NA & NA & NA & NA & NA & NA & NA \\
Leptothecata & 1 & 1 & 1 & 1 & 100 & 100 & 100 & 85 & 100 \\
Anthoathecata & NA & NA & NA & NA & NA & NA & NA & NA & NA \\
Filifera I + II & 0.91 & 1 & NA & 1 & 41 & 42 & 75 & NA & 80 \\
Apla + Capit & NA & NA & NA & NA & NA & NA & NA & NA & NA \\
Apla + Fili I-II & 0.61 & 1 & NA & 1 & NA & NA & 36 & NA & 66 \\
Apla + Capit + Fili I-II & NA & 1 & NA & 1 & NA & NA & 80 & NA & 81 \\
Lepto + Fili III-IV & 1 & 1 & NA & 1 & 91 & 91 & 91 & NA & 91 \\
Sipho + Apla & NA & NA & NA & NA & NA & NA & NA & NA & NA \\
Sipho + Lepto & NA & NA & NA & NA & NA & NA & NA & NA & NA \\
Antho + Lepto & 0.68 & 1 & NA & 1 & NA & NA & 78 & NA & 80 \\
\hline
\end{tabular}

